\title{
Imre Gráfik
}

\section{Der Sattel \\ Unser östliches Kulturerbe}

\author{
The Saddle \\ Our Eastern Cultural Heritage
}

\begin{abstract}
The study summarizes the most important knowledge about the saddle, the eastern heritage of Hungarian culture, based on the results of the research and an exhibition. Animal husbandry, especially keeping horses, has always played a very important part in Hungarians life. Saddling horses was significant up until the middle of the 20th century in Hungary, we have information about it from noblemen, the aristocracy, the upper social stratas, as well as from peasants and market town inhabitants. Objects and memories connected to riding culture, riding as a way of life, were present in the memory of the upper social classes and in folklore. There were different types, varieties of saddles, just as there were varieties of almost all the objects in our culture, depending on who used them and for what purposes. In general we can say that as the terms and conditions of life changed so objects were transformed and developed. The same is true for saddles, they belong to a group of objects which gained their final, almost perfect shape very early in time, so very few changes were made to them. The saddles used by Hungarians were very suited to riding. The big advantage of wooden saddles is that they spare horses. There are two basic types of saddles usually known as the western and eastern types. From a professional point of view, on the basis of examined material, we speak of the pommelsole/panel type and the fork-side panel/bar type. The Hungarian saddle belongs to the Eastern type. A unique and famous variety of the Hungarian saddle is the Tiszafüred saddle. Light cavalry equipped with Hungarian harness spread around Europe, so Hungarian type saddles (Hussar saddle) were an essential part of military equipment. Nowadays there is an increased interest in the riding tradition, and the historical past, and attention is focused on the Hungarian wooden saddle that has been used successfully over the centuries.
\end{abstract}

Keywords: Horses husbandry, the Saddle, eastern type; pommel-sole/panel saddle, western type; fork-side panel/bar saddle, Hungarian wooden Saddle, the Saddler, Saddle from Tiszafüred/Tiszafüred Saddle, Hussar/cavalry Saddle, horse/riding culture

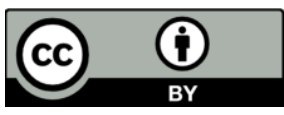




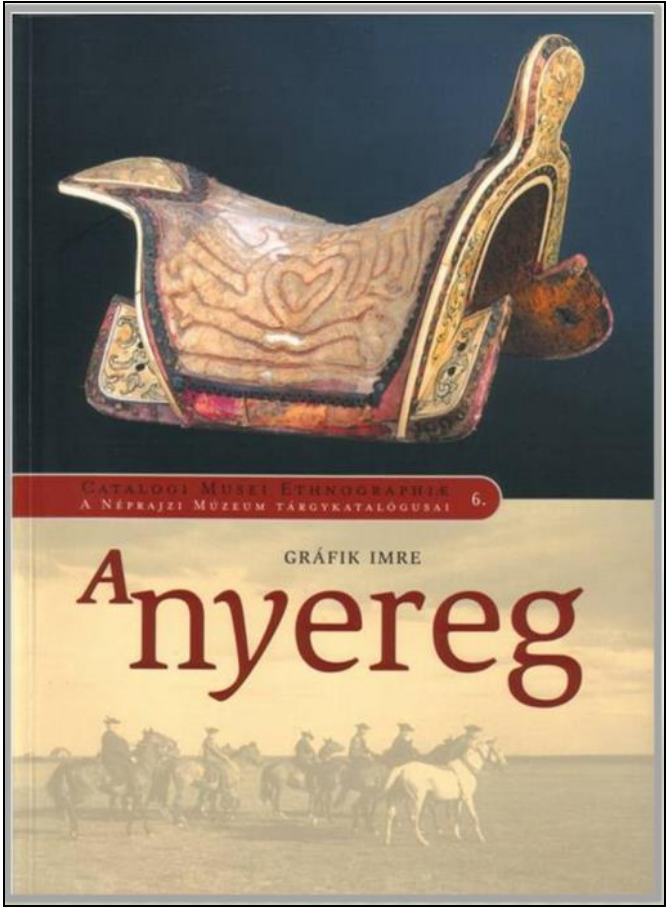

Bild. Nr. 1a: Der Sattel - Kunstwerkkatalog

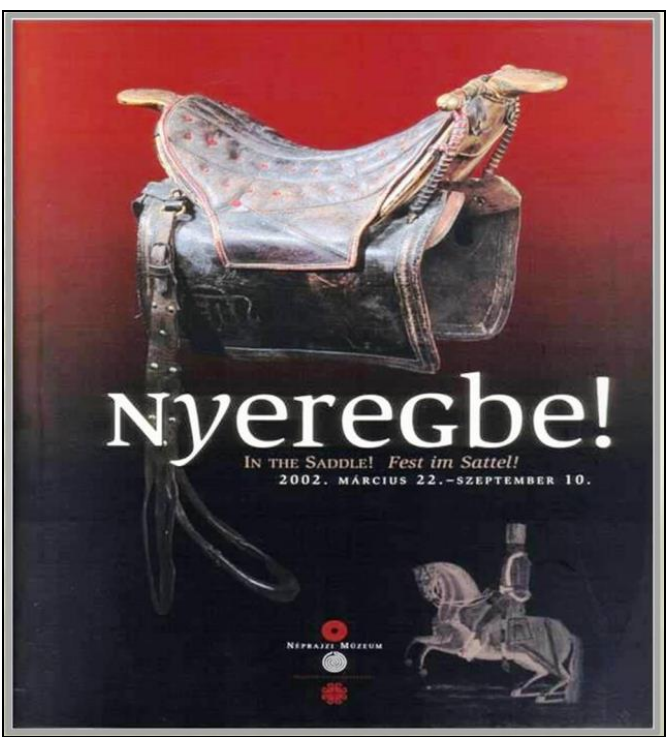

Bild. Nr. 1b: Fest im Sattel! - Ausstellungskatalog 
Die Pferdezucht hatte eine wichtige Rolle im Leben der im Karpatenbecken angesiedelten Ungarn. Die Bedeutung des Reitens ist in Ungarn seit der Landnahme (896 n.Chr., d.h. im 9. Jahrhundert) bis zur Hälfte des 20. Jahrhunderts zu beobachten. Die Gegenstände - unter ihnen die verschiedenen Sättel -, die mit der reitenden Lebensweise und Kultur zusammenhängen, waren gleichermaßen unter den Erinnerungsstücken der höheren Gesellschaftsschichten und der volkstümlichen Bildung zu finden.

\section{Über den Sattel}

So wie fast jeder feste Bestandteil unserer gegenständlichen Kultur, so durchlief auch der Sattel viele verschiedene Stadien, Typen und Formen, je nachdem, wer ihn zu welchem Zweck oder Anlass bestieg. Mit den Jahrhunderten wandelten sich die Lebenswelten und -bedingungen, und parallel dazu entwickelten sich auch unsere allseits bekannten Gegenstände. Der Sattel stellt hier keine Ausnahme dar, obwohl eingeräumt werden muss, dass er zu jenen Kulturgütern gehört, die schon sehr früh ihre optimale funktionelle Form und Struktur erhielten, sodass er im Lauf der Zeit kaum geändert werden musste.

Der ungarische Begriff für Sattel, nyereg (,nerg“, „närg”), gehört der Sprachwissenschaft zufolge zum sprachlichen Urerbe aus der ugrischen Zeit. Dies wird auch von den wogulischen und osztjakischen Formen bestätigt. Im obi-ugrischen kam es zu einer Lautumstellung in der Konsonantenverbindung im Wortinneren. Die ugrische Grundform mag „närk3“ gelautet haben. In der ursprünglichen Bedeutung bezeichnete das Wort vermutlich die dem Tier aufgebürdete Last, die seinem Rücken aufgebundene Decke usw., und sein Ursprung steht wohl im Zusammenhang mit der Pferdehaltung zu ugrischen Zeiten.

Die Bedeutung der Reitkunst im ungarischen Lebensalltag dauert mehr oder weniger bis in die Mitte des 20. Jahrhunderts an und kann für sämtliche gesellschaftlichen Schichten und Klassen, wie Hoch- und Kleinadel, Bürgertum, Bauernstand, Land- und Stadtbewohner gleichermaßen gut dokumentiert werden.

Jene Gebrauchsgegenstände, die einen so untrennbaren Teil der Reitkultur darstellen, wie der Sattel, stellen nicht nur das Erbe der höheren Gesellschaftsschichten dar, sondern gehören generell der Volkskultur an.

Die von den Ungarn benützten Sättel entsprachen hervorragend den verschiedenen Anforderungen der Reitkultur, wie Fernritte, Ritterkämpfe usw. Eine der besten Eigenschaften der hierzulande bekannten Holzsättel ist, dass 
sie das Pferd schonen. Der Sattel selbst ist leicht, sein Gewicht - auf das Gerippe bezogen - beträgt ganze 1,5 bis 2,5 kg. Wird das Pferd richtig gesattelt, dann reibt er den Rücken des Tieres nicht wund und behindert es weder im Schritt noch im Galopp. Dem Reiter wiederum sichert der Sattel, neben dem Gefühl der Sattelfestigkeit bei Verwendung des Zügels, die notwendige Beweglichkeit seitwärts und rückwärts, was insbesondere bei berittenen Kampfhandlungen ausschlaggebend war.

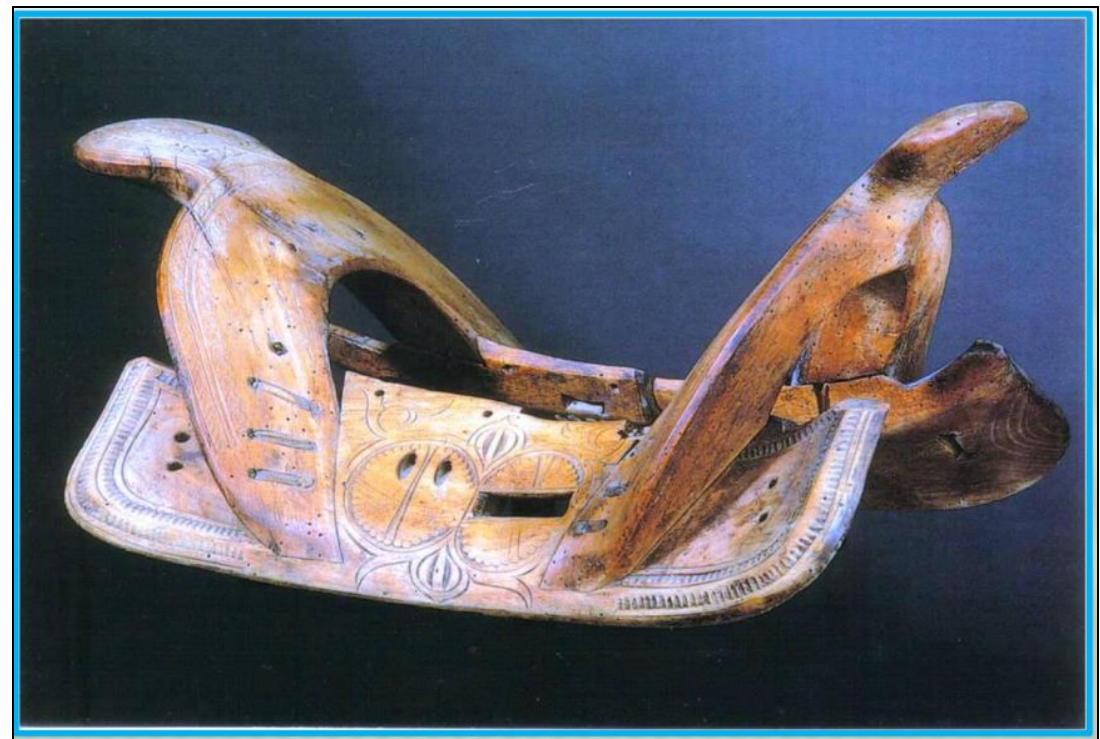

Bild. Nr. 2: Sattel, Sattelrahmen/Sattelgerüst. NM 69.27.4

Der Satteltyp und dessen Formgebung werden grundsätzlich von seinem strukturellen Aufbau bestimmt, von der Art bzw. vom Fehlen oder Vorhandensein des Gerippes, des sogenannten Sattelbaumes.

Das Sattelgerippe wurde ursprünglich aus Holz hergestellt, es gibt aber auch Varianten aus Knochen oder mit Knochenverzierungen, eventuell auch aus Leder bzw. mit Ergänzungen aus Leder sowie aus Metall (Eisen oder Stahl). Die Holzsättel - die den überwiegenden Teil der Sammlung des Ethnografischen Museums ausmachen - wurden aus vier bis sechs Teilen zusammengestellt (geschnürt, gebunden, gezapft, genagelt, geschraubt). Zwei Teile bilden den Sattelfuß, der auf dem Pferderücken aufliegt. Diese Fußteile oder Polsterbölzer werden auch Sattelflügel oder Sattelbretter genannt. Die Sattelflügel werden vom Sattelkopf oder Zwiesel (Vorderzwiesel und Hinterzwiesel) aus zwei oder vier Stücken zusammengehalten. 


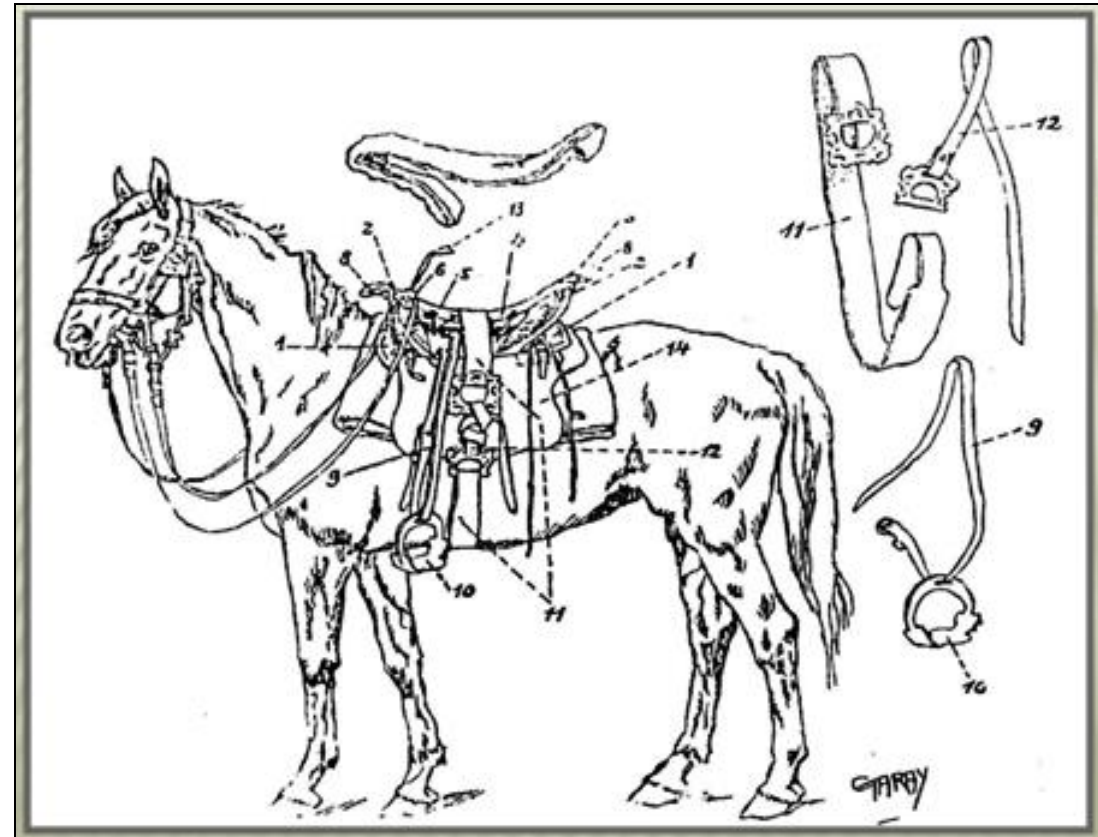

Bild. Nr. 3a: Sattelung in der ungarischen Tiefebene (Garay 1936).

Die einzelnen Teile wurden derart aneinandergefügt, dass auf das Rückgrat des Pferdes kein Druck ausgeübt wurde. Darum blieb die Mitte des Sattels bzw. des Gerippes im Allgemeinen leer, dies wurde Sattelkammer genannt. Zur Überbrückung der Sattelkammer und zur Ausformung der Sitzfläche wurden mehrere fingerbreite Hinter-bzw. Fabrleder, manchmal auch Leinengurte, um das Gerippe gewickelt.

Obwohl die Sattelflügel, die direkt auf dem Pferderücken aufliegen, zumeist mit Leinen umwickelt wurden, konnte unter dem Sattel auch noch eine sogenannte Schweißdecke zu liegen kommen.

Das Sitzpolster (Sattelkissen) bestand aus verschiedenen Füllmaterialien (z.B. Tierhaar) sowie aus Leinen- und Lederbezug. Der Sitz selber wurde vor allem bei Ziersätteln - aus edleren Materialien hergestellt und gegebenenfalls mit einer kunstvoll gestickten sogenannten Schabracke bedeckt. Fallweise wurde diese Ausstattung durch eine Seitendecke ergänzt, zumeist aus Leder.

Der Sattel wurde mit Riemen und Gurten (Brustriemen, Schweifriemen, bzw. Vordergurt/Lastgurt und fallweise Hintergurt) auf dem Pferderücken festgezurrt.

Unabkömmlich für das sichere Reiten sind die unterschiedlich geformten Steigbügel aus verschiedenen Materialien (Holz, Eisen, Bronze), die an Riemen (Steigriemen) vom Sattel herunterhängen. 


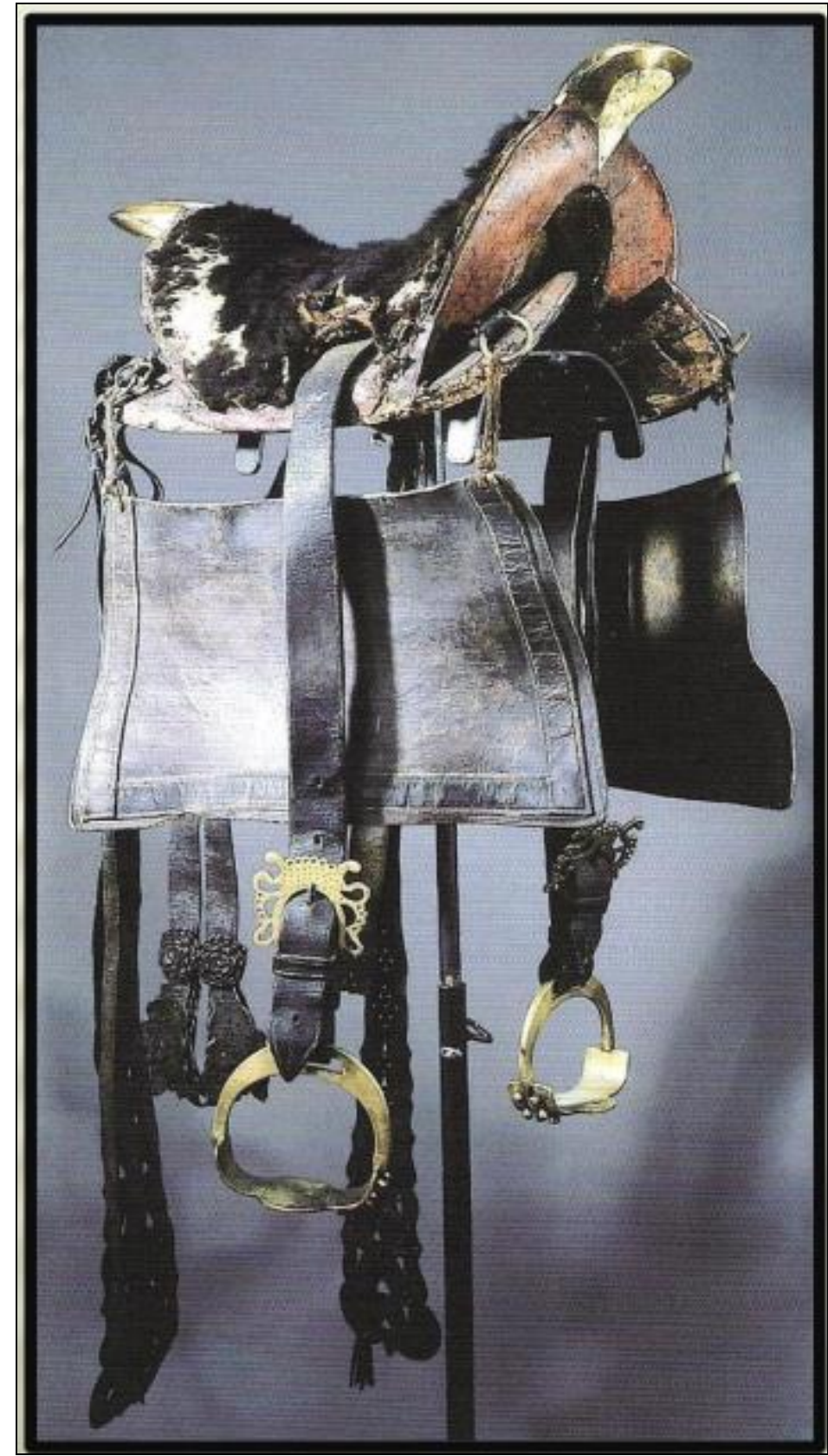

Bild. Nr. 3b: Sattel mit voller Ausrüstung (mit sogenannten Ledersattelflügeln). NM 60.108.10 
Einige Sättel wurden beiderseitig mit abwechslungsreich verzierten Behängen versehen. Diese Schalanken wurden zumeist von denselben Sattlermeistern erstellt, die auch die Sättel herstellten. Zu ihrer ästhetischen Verzierung wurden Techniken wie Durchstechen, Flechten, Pressen, Relief und Applikation verwendet.

Als weitere Bestandteile des Sattels gelten noch Zügel, Zaumzeng (bei Gespannen die Beizügel) und verschiedene Trensen.

Die europäischen Sättel können allgemein in zwei Grundarten eingeteilt werden, je nach struktureller Eigenart. In der Umgangssprache werden diese Kategorien östlicher bzw. westlicher Typ genannt. Von beiden Grundarten sind selbstverständlich zahlreiche Variationen bekannt, je nach Gebiet, Stand und Funktion. Reich verziert und individuell ausgeführt wurden in erster Linie die Sättel des Hochadels, der Herrscherhäuser und der Damen.

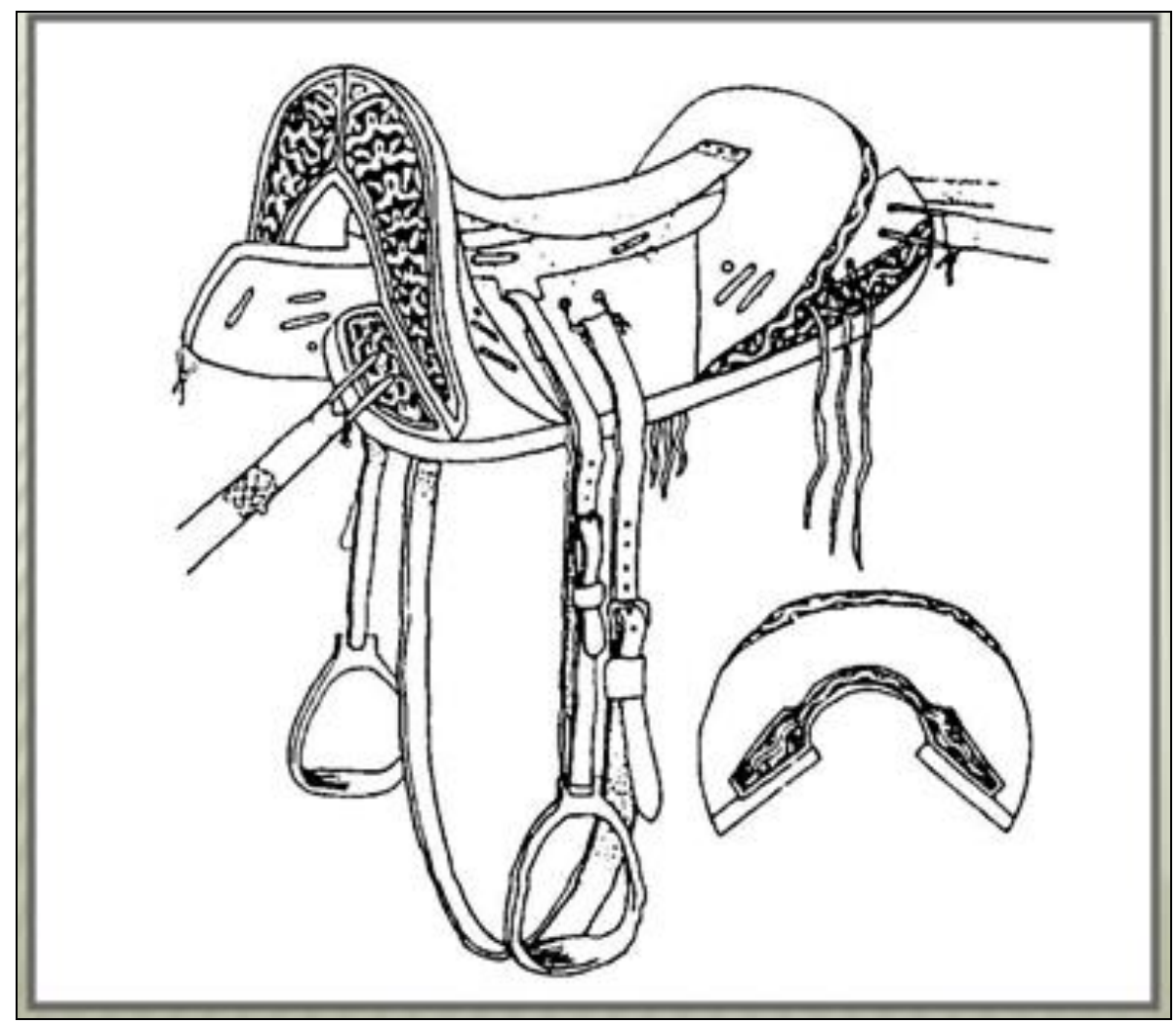

Bild. Nr. 4a: Rekonstruktion des Sattels aus Soltszentimre (László 1974). 


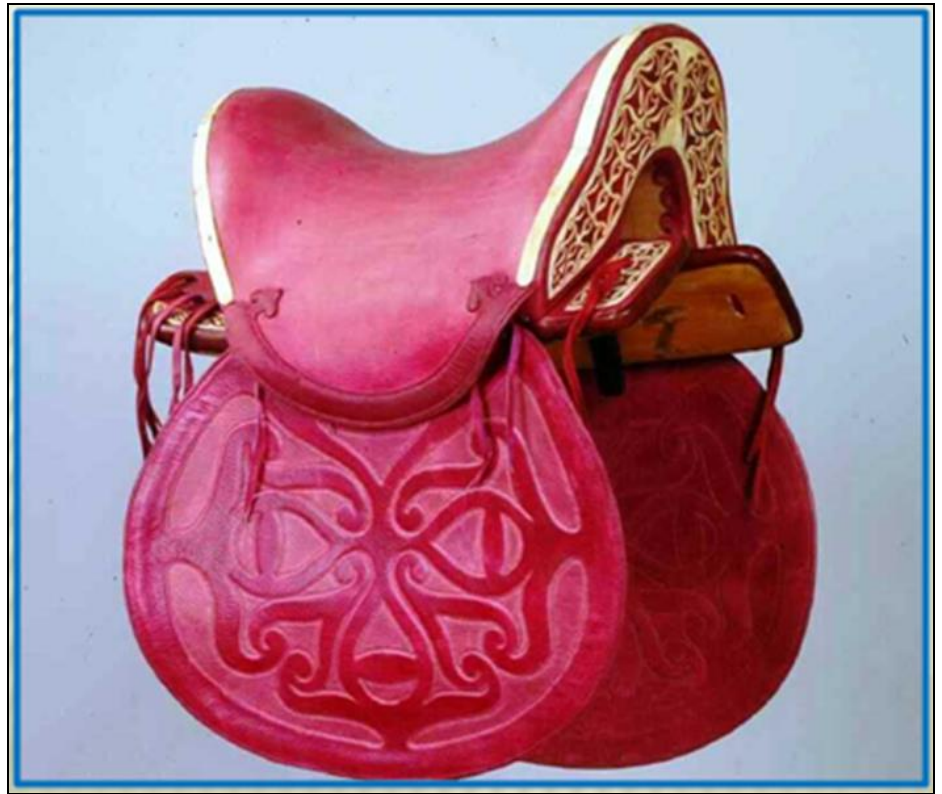

Bild. Nr. 4b: Rekonstruktion des Sattels aus Soltszentimre, von Attila Pánczél, Márta Lobmajer.

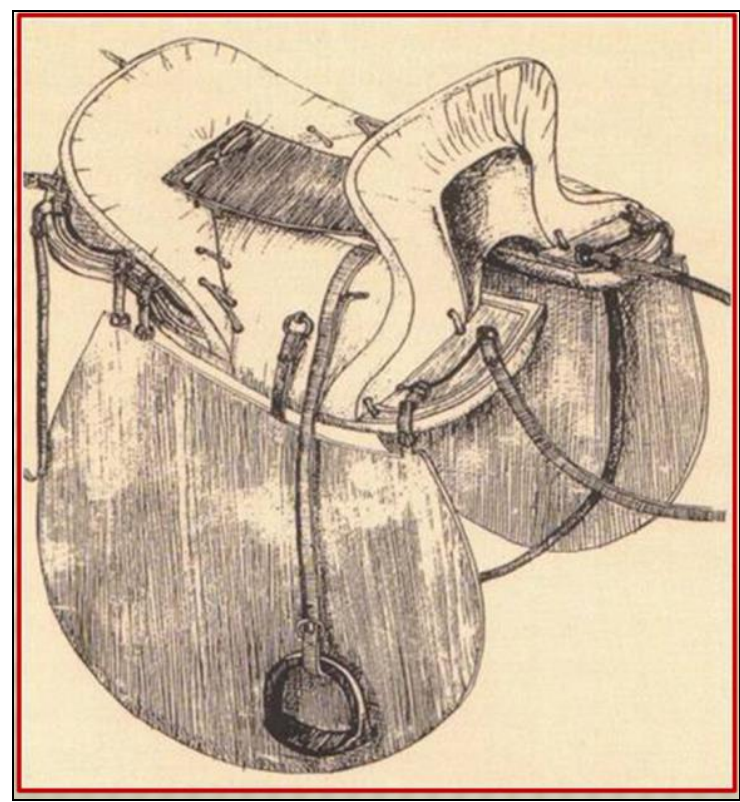

Bild. Nr. 5a: Die Rekonstruktion des Sattels aus Khovd, Mongolei (U. Kőhalmi 1968). 


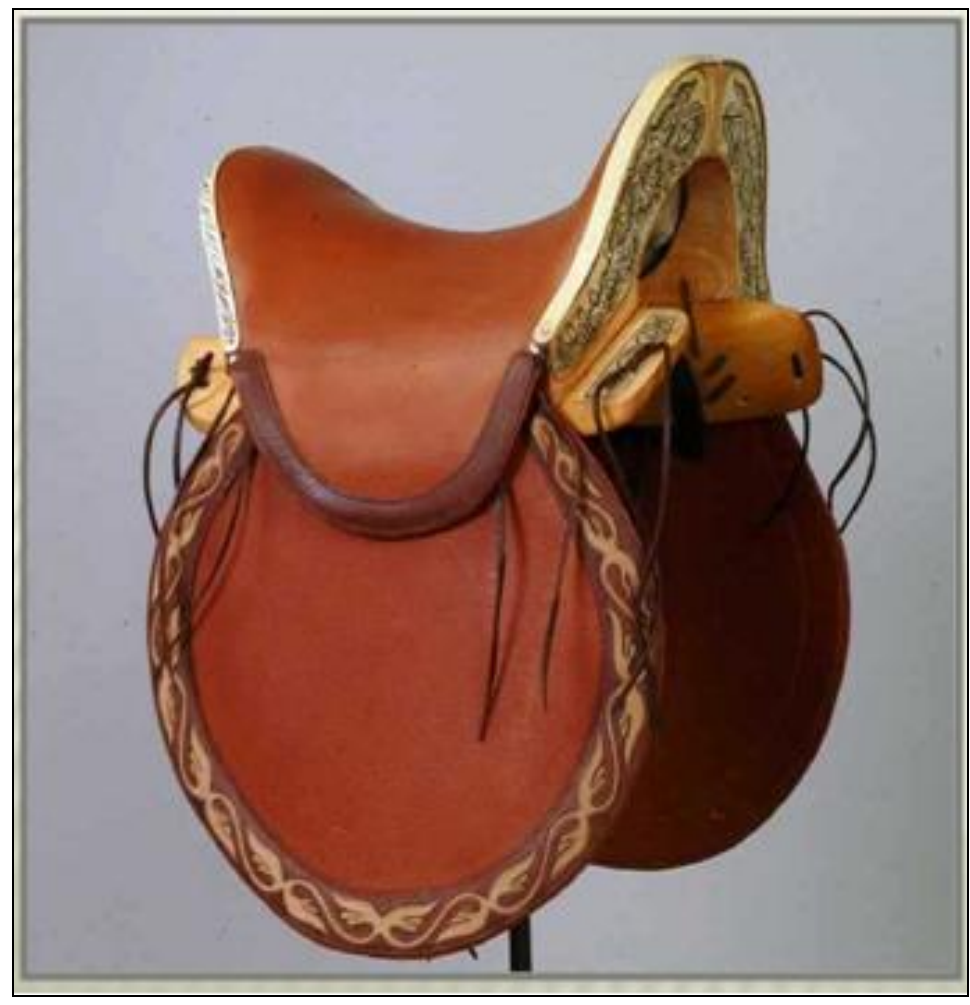

Bild. Nr. 5b: Rekonstruktion des Sattels aus Izsák Balázspuszta, von Attila Pánczél, Márta Lobmajer.

Die Entwicklungsgeschichte der Sättel wurde in der ungarischen Fachliteratur zuerst von Gyula László untersucht, insbesondere auch hinsichtlich ihrer Funktion im Leben der östlichen Nomadenvölker. Zuletzt fasste Katalin U. Köhalmi den Stand der Forschung zusammen. In Kenntnis der historischen Daten und sonstigen Quellenmaterials gilt es als wahrscheinlich, dass der Sattel irgendwo in Asien „erfunden“ wurde und dort bereits in mehreren Varianten verbreitet war, die im Zuge der Völkerwanderungen nach Europa gelangten. In das Karpatenbecken brachten ihn vermutlich zuerst die Skythen oder die Hunnen und Awaren.

Rein fachlich gesprochen, wäre es aufgrund des ausgestellten und untersuchten Materials eher angebracht, grundsätzlich zwischen den beiden Grundtypen Zwiesel-Flügel-Sättel und Gabel-Seitenbrett-Strukturen zu unterscheiden. Abgesehen von kleineren Details und Unterschieden, können wir diese beiden Typen folgendermaßen unterscheiden: 
Imre Gráfik

Zwiesel-Flügel-Sättel

(Östlicher Typ)
Gabel-Seitenbrett-Sättel

(Westlicher Typ)

- leichteres Gerippe und Ausstattung

- Zwiesel-Flügel-Struktur, d.h.

- schwereres Gerippe und Ausstattung

- horizontal, auf Flügelbretter gebaut

- relativ niedrig

- eher flacher Sattelkörper

- sog. Fahr-/Hinterleder-Brücke

- im Allg. breiterer Sitz

- Gabelstruktur, d.h.

- senkrecht, auf gabelartigen Zwiesel gesetzt

- relativ hoch

- steilerer Sattelkörper

- Brückenstruktur bzw. ,stuhlartig”

- schmälerer Sitz

- geleimt, vernagelt

Unter dem westlichen Typ versteht die Fachliteratur, insbesondere im Hinblick auf das Mittelalter, den sogenannten „Rittersattel“. Dessen Ursprung geht auf den „parthischen“ Sattel („Parthus”-Sattel) zurück. Der wurde von den Römern übernommen, und diese Strukturform verbreitete sich später in Westeuropa, und gen Osten zurückgekehrt, im ganzen südlichen Eurasien. Die Grundstruktur dieser Sättel wurde in Ungarn von den später weiterentwickelten - „belastenden“ Sätteln übernommen. Zwei gabelartige Zwiesel liegen hier unmittelbar auf dem Pferderücken auf, und die beiden werden beiderseitig von Hölzern zusammengehalten.

Der westliche Satteltyp wurde gegen Ende des Mittelalters durch den Niedergang des Rittertums in den Hintergrund gedrängt. Auch die berittene Kriegskunst änderte sich, wie ganz allgemein die Pferdehaltung und die Reitkunst, die immer mehr den bürgerlichen Bedürfnissen zu entsprechen suchte. Diesen neuen Bedürfnissen entsprach der sogenannte englische Sattel besser. In seinen Varianten breitete er sich deshalb immer weiter in Europa und in der Neuen Welt aus. Charakteristisch für den englischen Sattel (und seine Untertypen) ist die „Verkümmerung“ von Zwiesel und Gabel, die bei einigen Arten ganz fehlen und gleichzeitig die Sitzoberfläche aus Leder, in die das Gerippe eingearbeitet ist, und der speziell aus dem Ledermaterial herausgebildete Sattelkörper. 


\section{Der Sattel-Unser östlisches Kulturerbe}

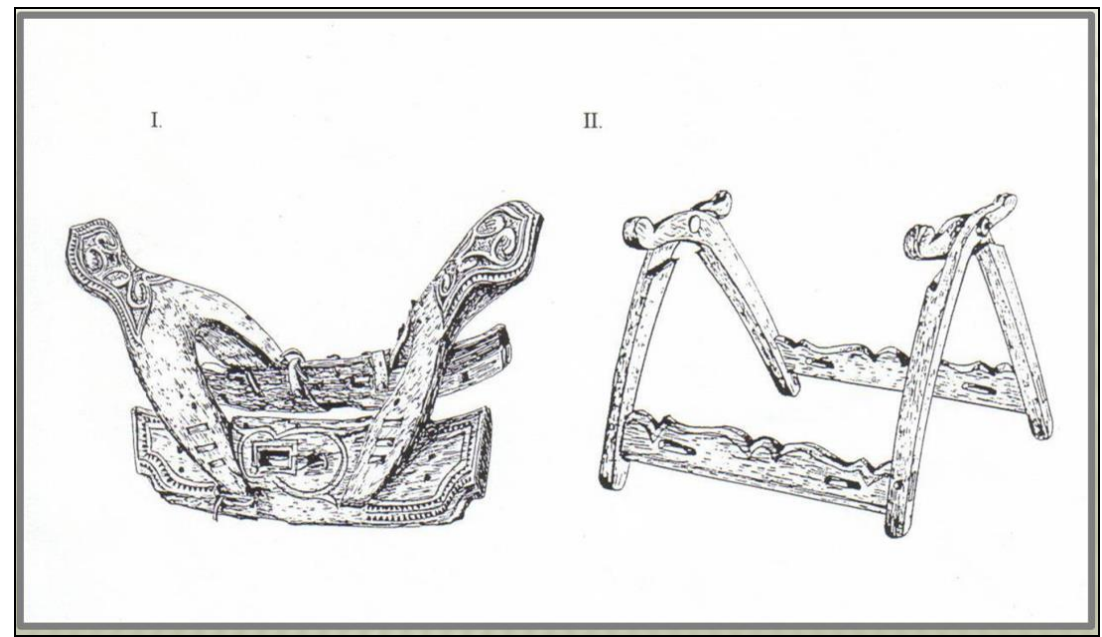

Bild. Nr. Ga: Beide Grundtypen: I. östlicher und II. westlicher Sattel-typ.

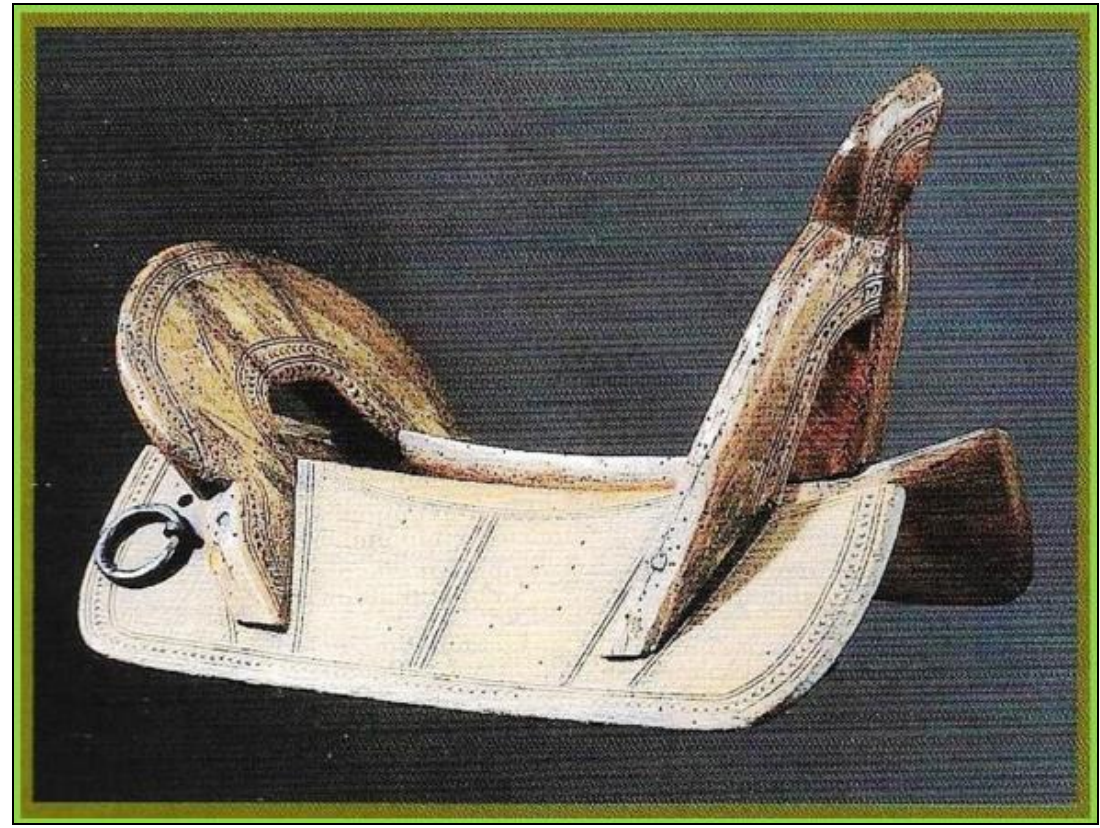

Bild. Nr. 6b: Sattelgerïst nur auf dem Vorderzwiesel mit Sattelknopf. NM 86646. 


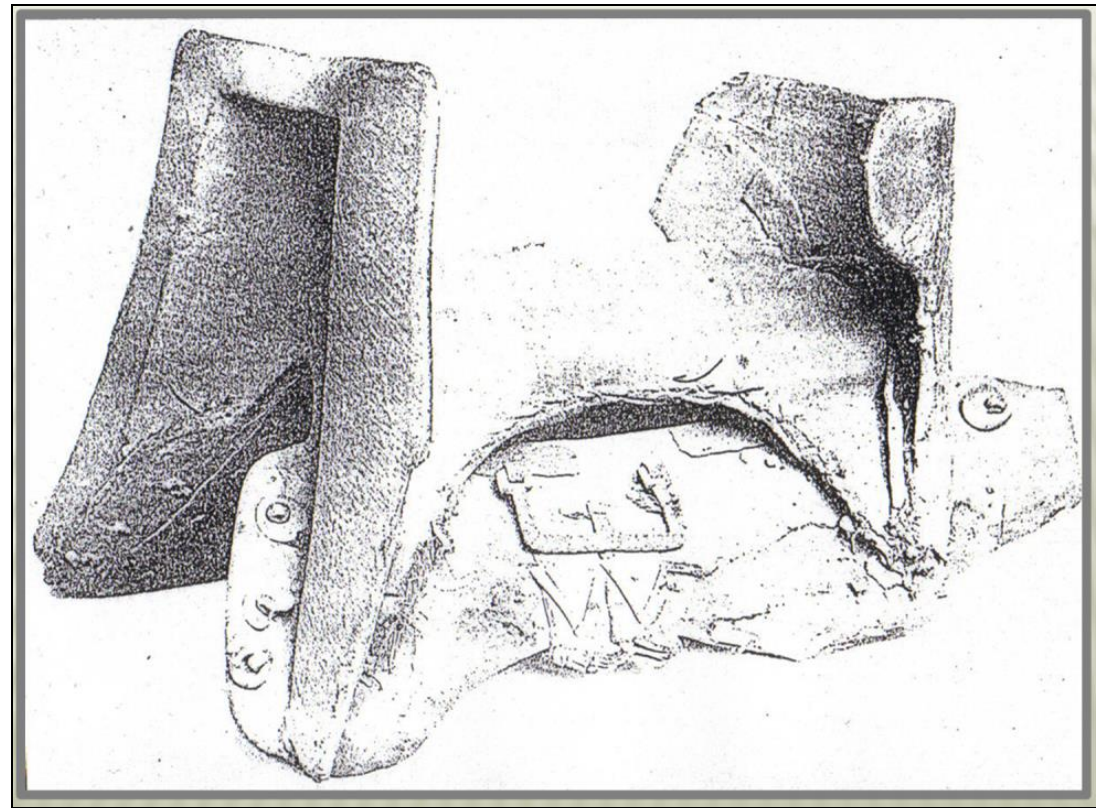

Bild. Nr. 6c: Rittersattel. (Laking 1920. III.). Sattel am Grab von König Heinrich V. in der Chantry Chapel (Westminster Abbey).

\section{Der ungarische Sattel}

Wichtigstes Merkmal des ungarischen Sattels ist, dass er ein ausgeprägter Osttyp ist. Er ist niedrig ausgeformt, seine bogenförmigen Zwiesel werden von Fahrleder zusammengebunden. Die Zwiesel, deren Kopf vorne herausgebildet ist, hinten nur bei einigen Varianten dominiert, werden mit Lederriemen zusammengehalten und/oder mit Zapfen an die Sattelfüße angefügt, die sich an den Pferderücken schmiegen. Der nach vorne geneigte Vorderzwiesel ragt empor, der Hinterzwiesel neigt sich meist zurück und ist rund ausgeformt, was einer bequemen, aber beweglichen Sitzhaltung entgegenkommt.

Angesichts der Abweichungen zwischen den beiden Grundarten können wir daher feststellen, dass es zwischen den lotrechten, auf einen Gabelzwiesel aufgebauten Sätteln und den waagrechten, auf die Sattelflügel aufgesetzten Sätteln grundlegende Unterschiede gibt. Letzterer liegt nur an zwei Punkten auf dem Pferd auf, und hier kommt auch der Gurt zum Einsatz, während die abgerundeten Sattelflügel das Pferd in keiner Weise in seiner Bewegung beeinträchtigen. Die Sattelflügel ermöglichen auch die Ausbildung des beque- 
men hinteren Zwiesels, an den man sich anlehnen kann, und die Entfernung zwischen den beiden Zwieseln ist hier größer als bei den Gabelsätteln. In diesem Sattel kann sich der Reiter daher frei bewegen, wenden und hin- und herbeugen, und so eignete er sich etwa für das Bogenschießen nach hinten und für den berittenen Nahkampf. Diese Eigenschaften wurden durch eine entscheidende Neuerung begünstigt, dem Steigbügel. In ihm gewinnt der Reiter sozusagen sicheren Boden, seine Beine können sich abstützen, und er kann im Sattel aufstehen.

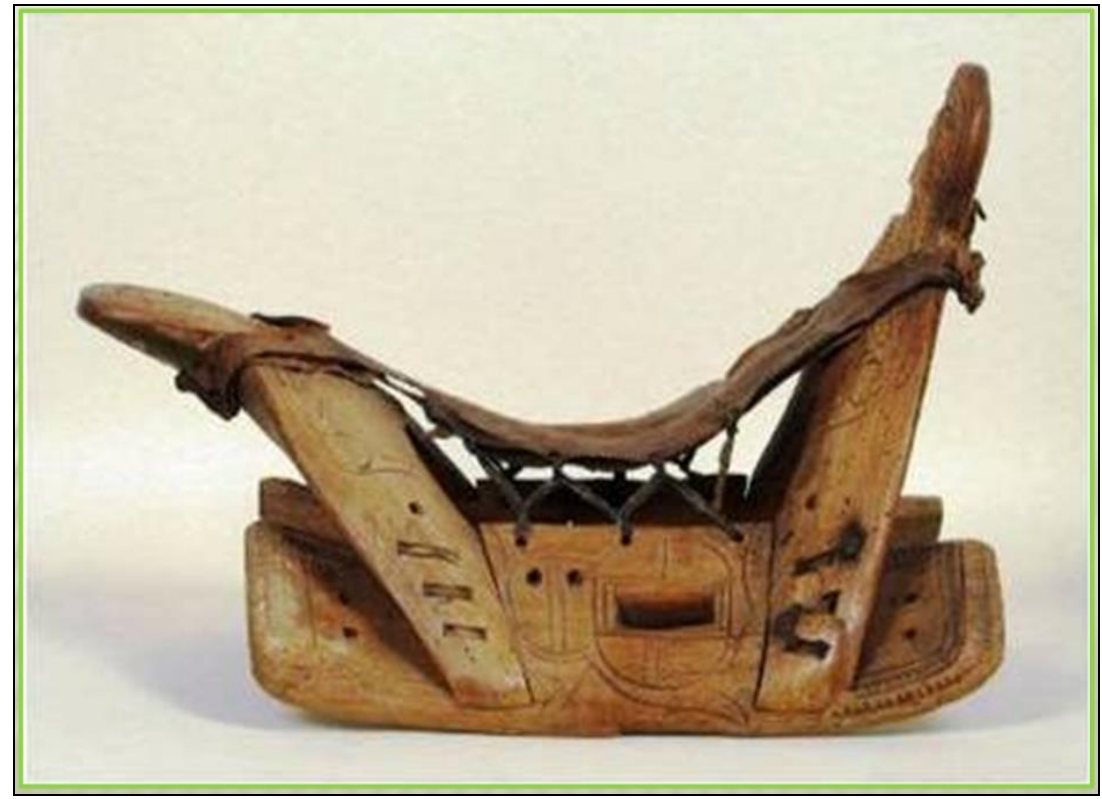

Bild. Nr. 7: Holzsattel, Muгej Vojvodine, Novi Sad, Srbija.

Aufgrund des archäologischen Befundes, einschließlich der Rekonstruktionen, der Miniaturabbildungen zeitgenössischer Chroniken und Kodexe, sonstiger künstlerischer Abbildungen und des eher wortkargen einschlägigen Quellenmaterials sowie aufgrund vergleichender ethnografischer Daten der heimischen Volkskunde können wir uns mit relativer Sicherheit ein Bild von dem ungarischen Sattel machen, wie er von den Magyaren zur Zeit der Landnahme verwendet wurde, sich im Laufe des Mittelalters umwandelte und doch seine Form und Ausbildung bewahrte. Basierend auf dem recherchierten und analysierten Material haben wir auch die verschiedenen Konstruktionsvarianten in einer Ausstellung vorgestellt. 
Im Mittelalter wurde der später „ungarischer Sattel“ genannte Typ durch den Siegeszug der gepanzerten Ritterschaft verdrängt, die einen anders aufgebauten Sattel verwendete. Die leichtere berittene Kampftechnik, deren Effektivität sich zur Zeit der Zurückdrängung der türkischen Herrschaft bewährte, verschaffte dem ungarischen Sattel wieder Vorrang.

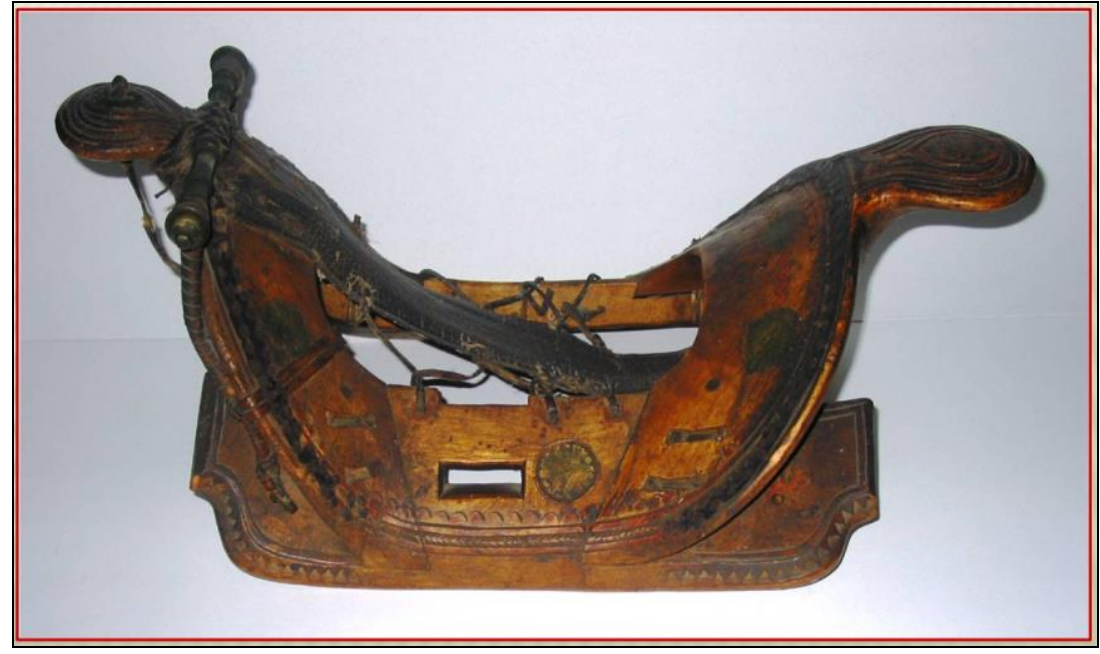

Bild. Nr. 8: Holzsattel, Finta Múreum, Túrkeve.

\section{Sattler und Sattler: Hersteller von Sätteln}

Jene Meister, die Sättel herstellten, wurden Sattler genannt. Auf Ungarisch ist das entsprechende Wort als Standesbezeichnung seit 1359 bekannt, und auch der Begriff Sattelmacher war gebräuchlich, wofür wir ab 1510 Aufzeichnungen kennen. Die Sattlermeister lebten und arbeiteten am Übergang zwischen den bauernständischen Handwerkern und den städtischen Zunft- oder Zechen-Handwerken. Einige Dörfer und Märkte entwickelten sich zu Zentren der Sattlerei. In den bedeutenderen Städten organisierte sich der Berufsstand auch in Zünften.

Aus dem Vermächtnis der Zünfte wissen wir mit einiger Genauigkeit, in welchen Siedlungen Ungarns Sättel hergestellt wurden. Die Sattler waren in der Regel gleichzeitig auch Riemer bzw. die Riemer beschäftigten sich auch mit der Herstellung von Sätteln, und sie organisierten sich bereits im 14. und 15. Jahrhundert zu einer Zunft. 
Über jene Zünfte, die sich nur mit Sattlerei beschäftigten, verfügen wir über Quellenangaben aus dem 16. Jahrhundert: Schässburg (Segesvár, Ro) 1510, Hermannstadt (Nagyszeben/Sibiu, Ro) 1545, Preschau (Eperjes/ Prešov, Sl) 1589, Kaschau (Kassa/Košice, Sl) 1591, Leutschau (Lö́cse/ Levoča, Sl) 1592, Käsmarkt (Késmárk/Kežmarok, Sl) 1614, Ödenburg (Sopron) 1670, Buda 1690, Deutsch-Liptsch (Németlipcse/Partizánska Lunpráa, Sl) 1728, Pest 1778, Debrecen 1783, Tiszafüred 1822; die meisten Quellen stammen aus Siebenbürgen, das im Zunftwesen allen voraus war, aus Oberungarn und aus den Zentralregionen.

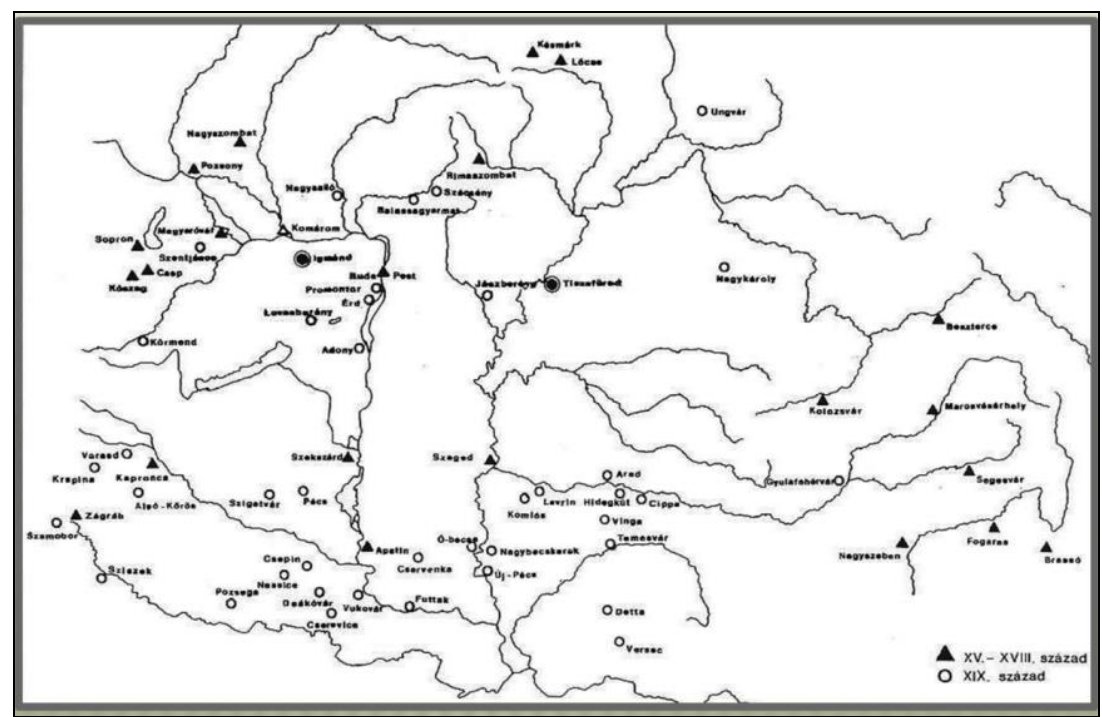

Bild. Nr. 9: Siedlungen, in denen sich mit Sattlerei beschäftigt wurde, vom Autor.

\section{Der Tiszafüreder Sattel und seine Hersteller}

Der Sattel von Tiszafüred (Stadt an dem Fluß Theiß im Nord-Tiefland Ungarns) war eine distinkte und berühmte Variante des ungarischen Sattels. Gyula László hat auf Grund der archäologischen Funde und durch die Arbeit des Sattelmeisters in Tiszafüred bewiesen, dass die in Tiszafüred gefertigten Sättel ihre Struktur aus der Zeit der Landnahme erhalten haben. Charakteristisch für diesen Typ, der ursprünglich in Tiszafïred hergestellt wurde und sich später ausbreitete, war die sehr niedrige Stellung und die Ausbildung des vorderen und hinteren Zwieselkopfes als sogenannter Zwieselläffel, der häufig mit Schnitzwerk verziert wurde. 
Aufgrund der neuesten Nachforschungen können wir die Sattlerei in Tiszafüred bis in die Mitte des 18. Jahrhundert zurückverfolgen. Darüber hinaus sind wir auf Vermutungen angewiesen.

Aufgrund des Quellenmaterials gehört die in der ersten Hälfte des 19. Jahrhunderts gegründete Tiszafüreder Zunft zu den späten Zünften. Aus Tiszafüred stammt gleichzeitig die genaueste Beschreibung der Sattelherstellung in unserem Besitz, und von allen regionalen Zentren der Sattlerei wissen wir am meisten über deren Geschichte in Tiszafüred, einschließlich der dort typischen Holzsättel mit Kunstschnitzerei.

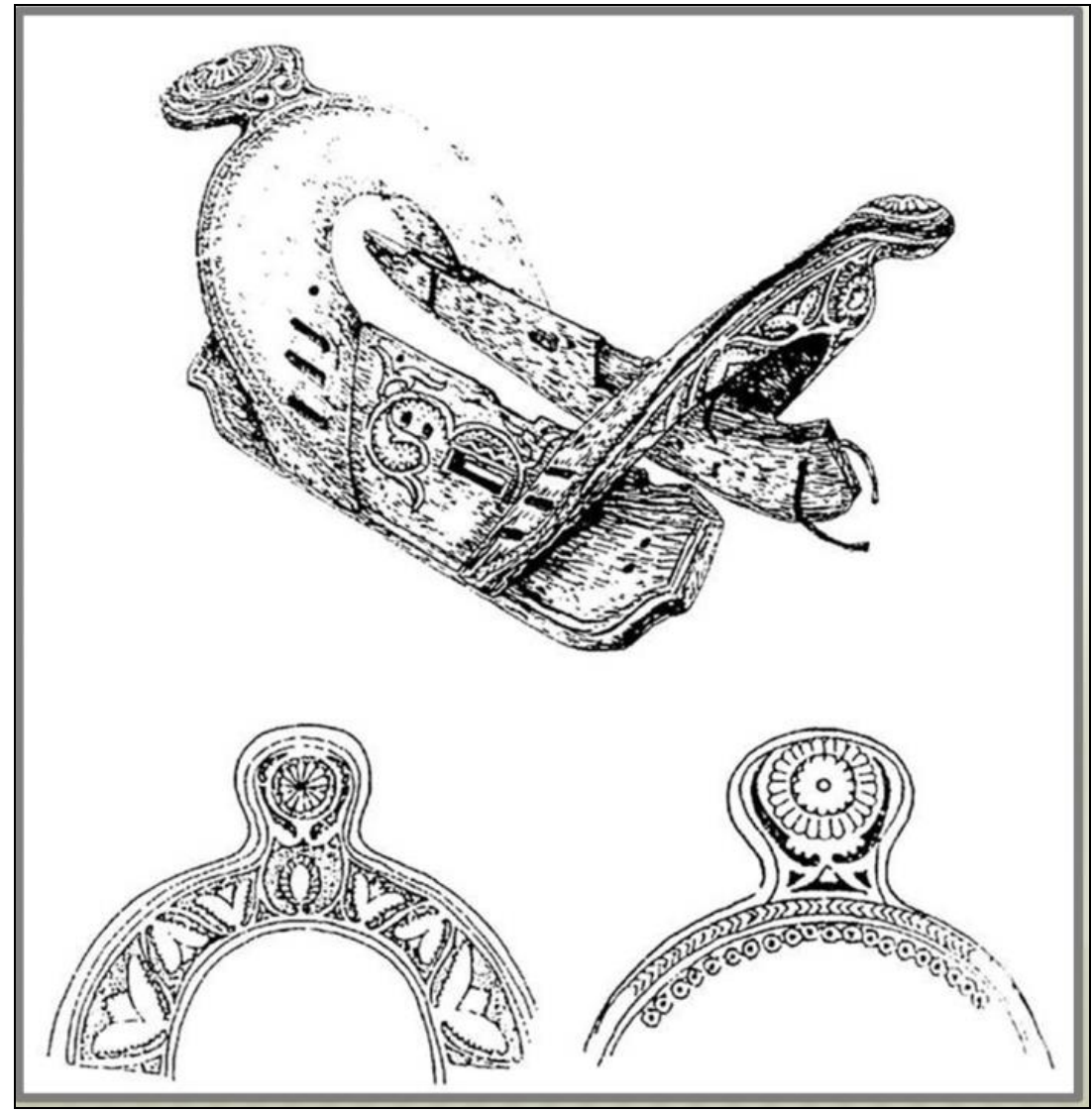

Bild. Nr. 10a: Zwiesel mit punziertem Hintergrund und Satteluntersatz-Schnitzereien. NM 56.32.157. 


\section{Der Sattel-Unser östlisches Kulturerbe}

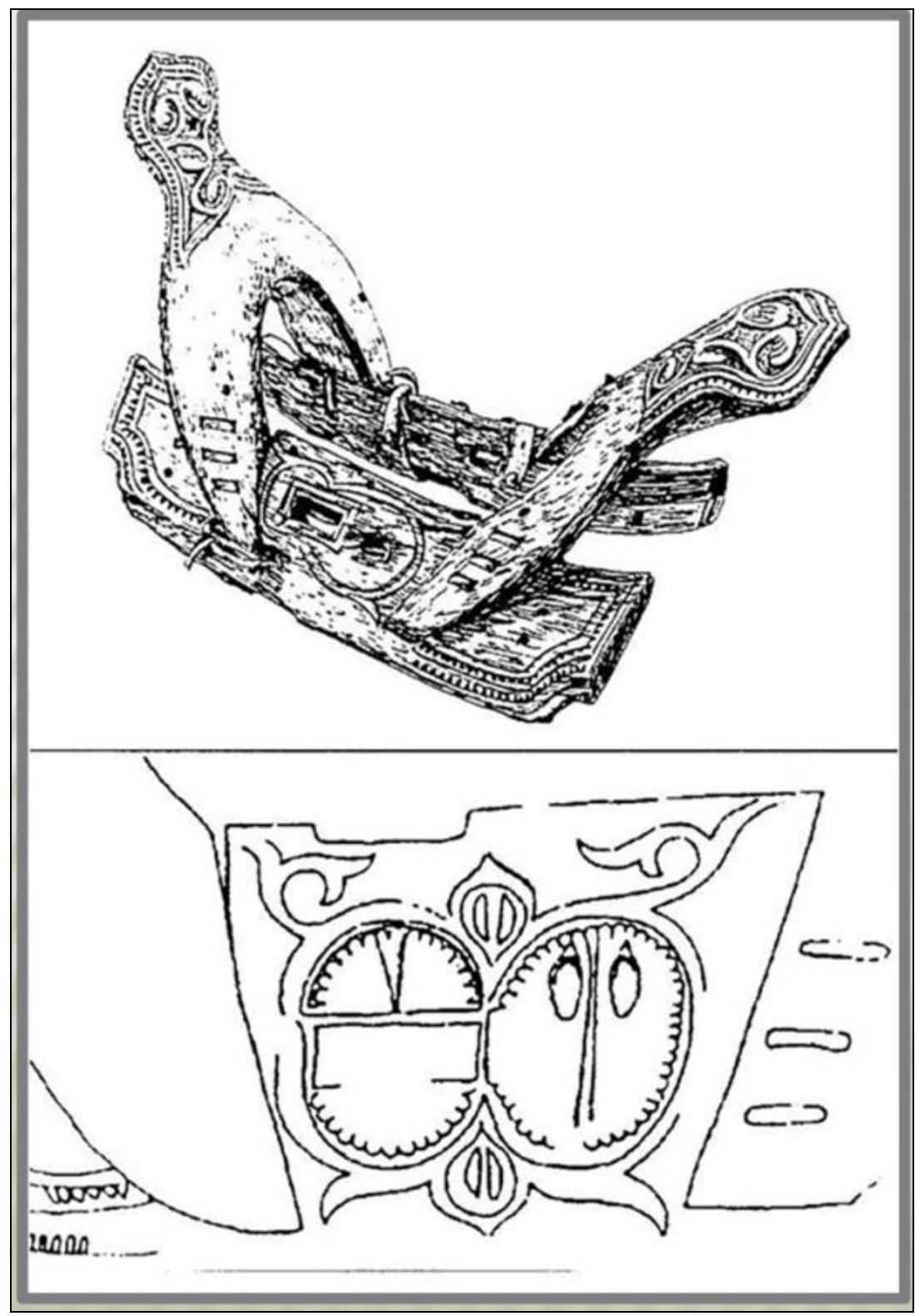

Bild. Nr. 10b: Geschnitzter Sattel, verziert mit punziertem Hintergrund und Satteluntersatz-Schnitzereien. 
Auf der Einberufungstafel der Tiszafüreder Sattlerzunft, die sich im Besitz des Ethnografischen Museums befindet, stehen zwei Jahreszahlen (1822 und 1849). Die ovale hölzerne Tafel ist ebenfalls mit Schnitzerei verziert, welche die Werkzeuge des Handwerks und einen Sattel aus der Vorderperspektive abbildet. Die Nachricht konnte in einem Seitenfach mit Schiebeverschluss deponiert werden. Auf dem Schieber sind Tulpenmotive zu sehen, auf deren in Spiralform endenden Stiel ist auch das auf den Zwiesellöffeln beliebte Palmettenmotiv vertreten. Die beiden Daten verweisen mit ziemlicher Sicherheit auf das Gründungsjahr sowie auf das Jahr der Erneuerung des Privilegs. Es gab auch einen Zunftstempel, der allerdings samt Privileg und Protokollen verlorengegangen ist. Nach Auflösung der Zunft wurden die Sattler 1876 Mitglieder des zweiten Handwerkerverbandes.Aus der goldenen Zeit der Tiszafüreder Sattler verfügen wir über Quellen, dass Füreder Sattler in der zweiten Hälfte des 18. Jahrhunderts auch im Ausland verdingt wurden. Der preuBische König Friedrich der Große ließ seine Kavallerie ganz nach ungarischem Muster ausstatten und ausbilden, wozu er ungarische Offiziere heranzog und gleichzeitig etliche Meister aus Tiszafüred anstellte, die in Preußen die Armee-Sattelbestände herstellten.

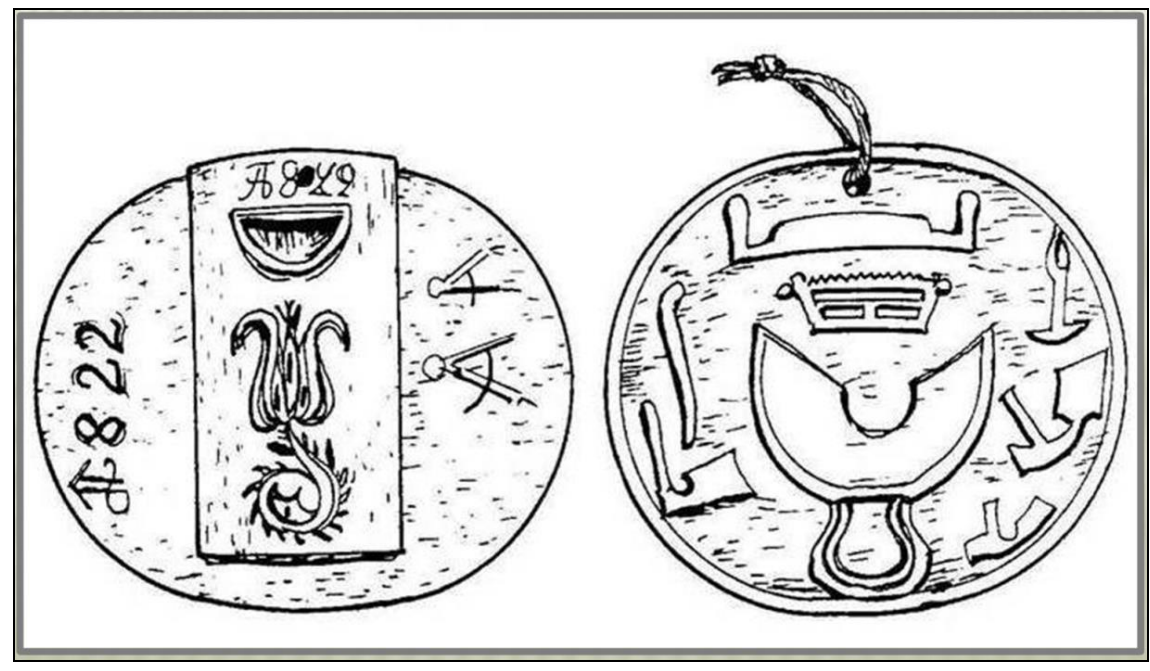

Bild. Nr. 11: Die Einberufungstafel der Sattlerzunft in Tiszafüred. NM 5.31.283. 


\section{Ungarische Sättel - Husarensättel}

Nach dem Muster des Husarentums verbreitete sich die leichte Kavallerie in ganz Europa, und mit ihr wurde über Jahrhunderte hinweg der ungarische Sattel als unabdingbarer Ausrüstungsgegenstand verbreitet. Die Husaren waren eine besondere ungarische Militärgattung von leichter Kavallerie. Aufgrund ihrer Kriegserfolge wurden sie europaweit bekannt, und nach dem Misserfolg des Rákóczi-Befreiungskampfes wurden die Husaren überall gern gesehen und verdingt. Aus diesem Grund breitete sich ab dem frühen 18. Jahrhundert diese typisch ungarische Gattung von Kavallerie auf vierunddreiBig Staaten dieser Welt aus.

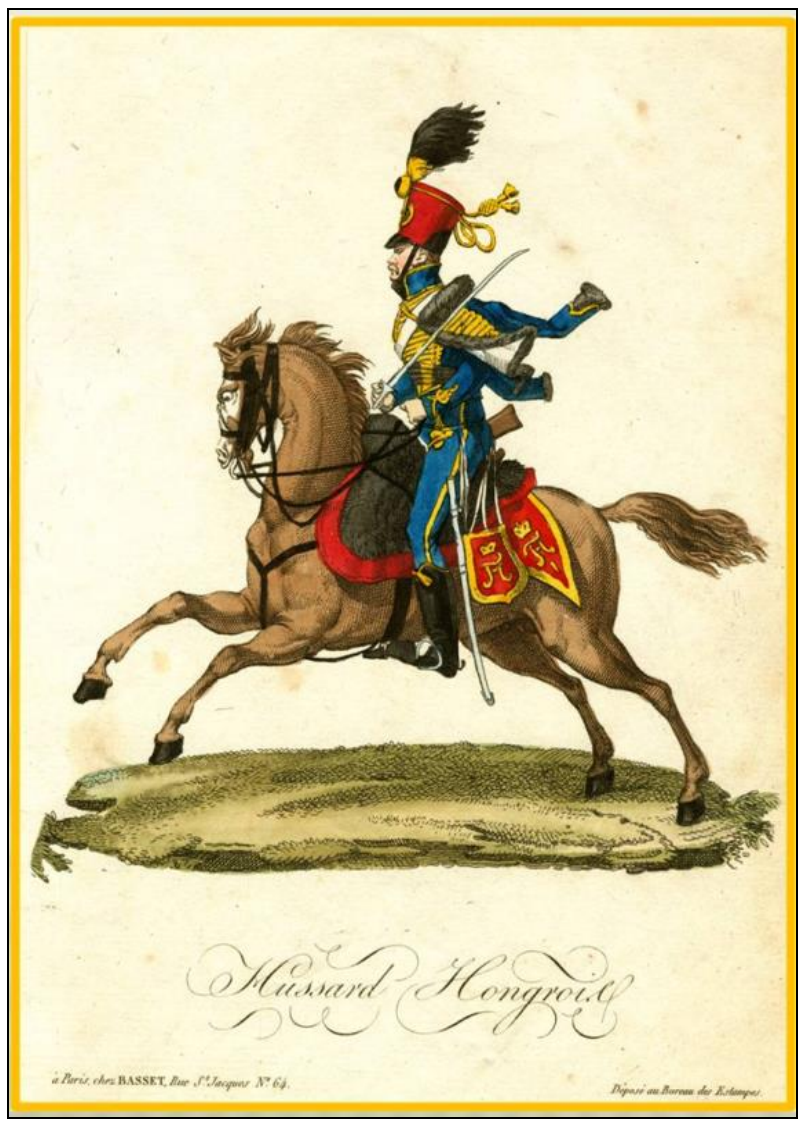

Bild. Nr. 12a: Hussard Hongroise 1830. (Privatsammlung). 
Imre Gráfik

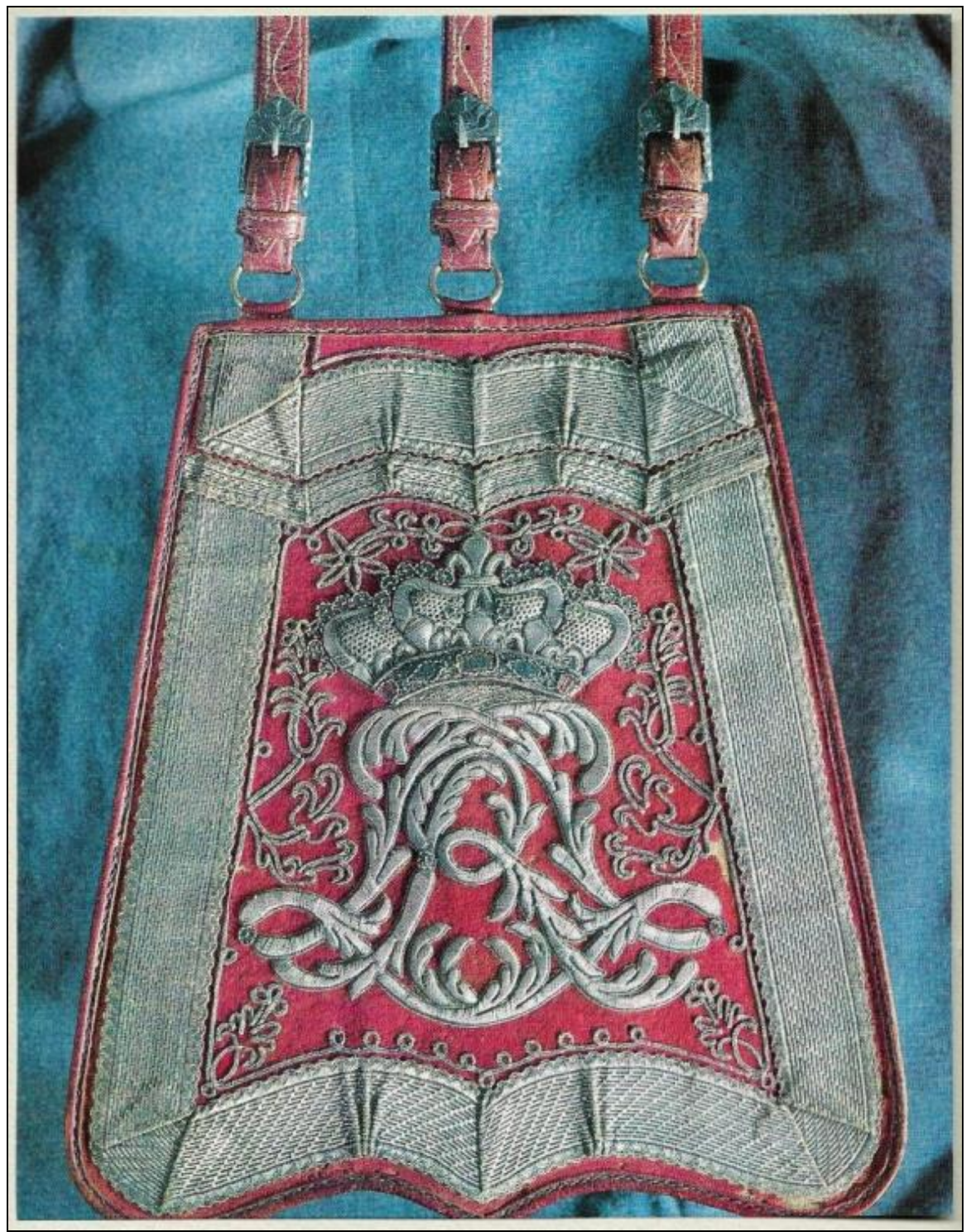

Bild. Nr. 12b: Offiziersdekorationstasche (ungarisch „tarsoly") von Husar Beræsenyi. (Le Musée International des Hussards, Tarbes). 


\section{Der Sattel-Unser östlisches Kulturerbe}

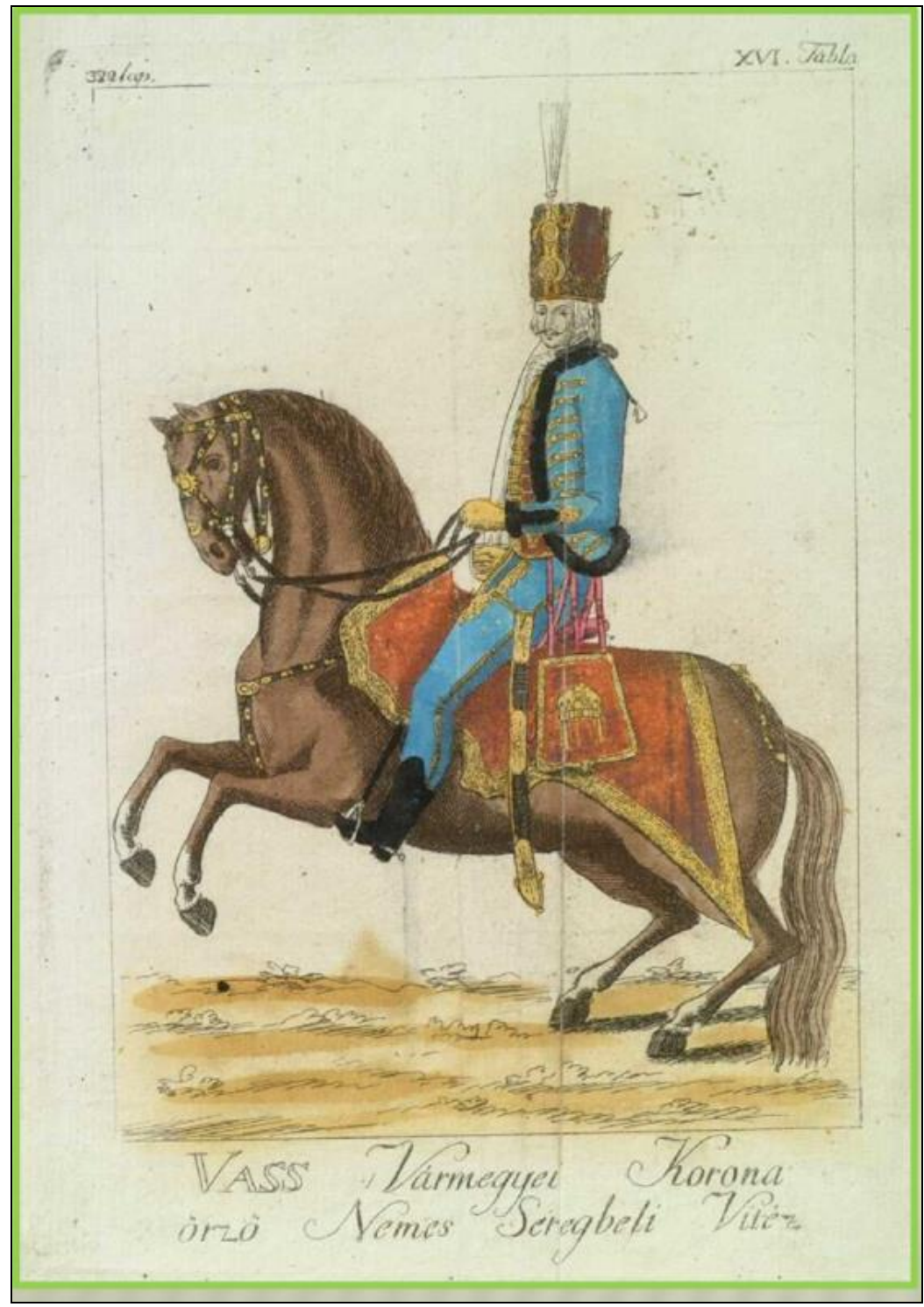

Bild. Nr. 12c: Aufständischer adeliger Kronbüter aus dem Komitat VAS, Magyar Történelmi Képcsarnok. 54.120. 


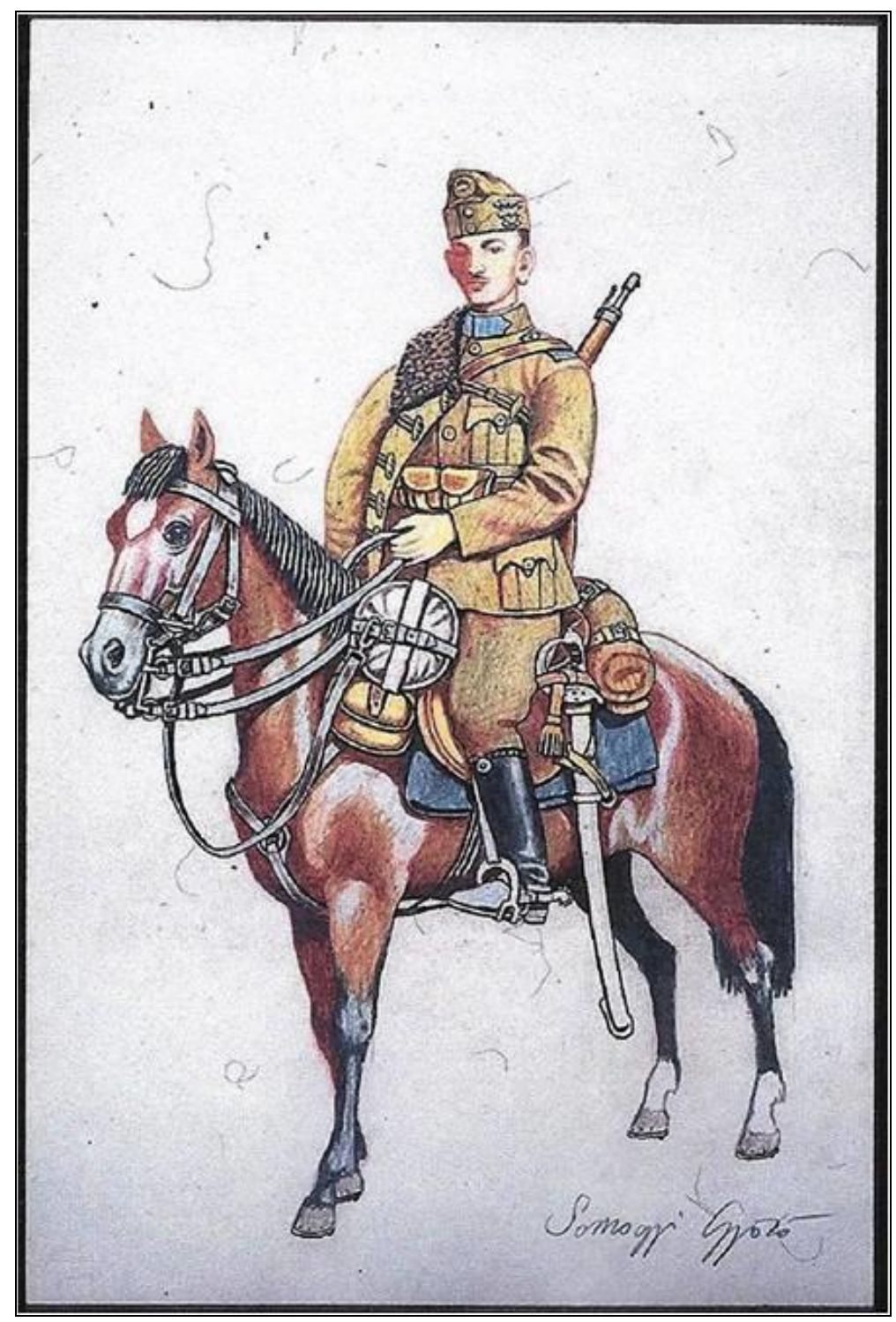

Bild. Nr. 12d: Der ,letəte Husar" 1940, Vater des Autors (Zeichnung von Győző Somogyi). 


\section{Der Sattel - Unser östlisches Kulturerbe}

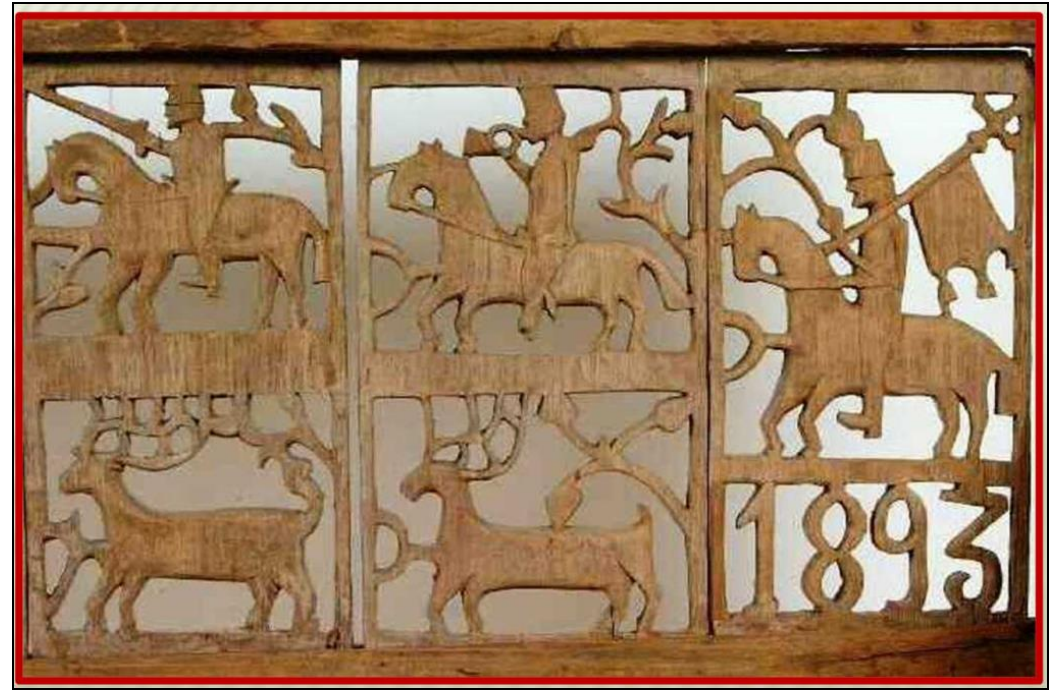

Bild. Nr. 13: Geschnitzte Banklehne. NM 73.193.1.

Im Rahmen der Ausstellung „,nyeregbe!““ (deut.: „Fest im Sattel!“; Ethnografisches Museum / Néprajæi Múreum, Budapest, 2002) setzten wir dem legendären ungarischen Husarentum mit Sätteln, zahlreichen zeitgenössischen Abbildungen und Kunstgemälden ein lebensechtes Andenken.

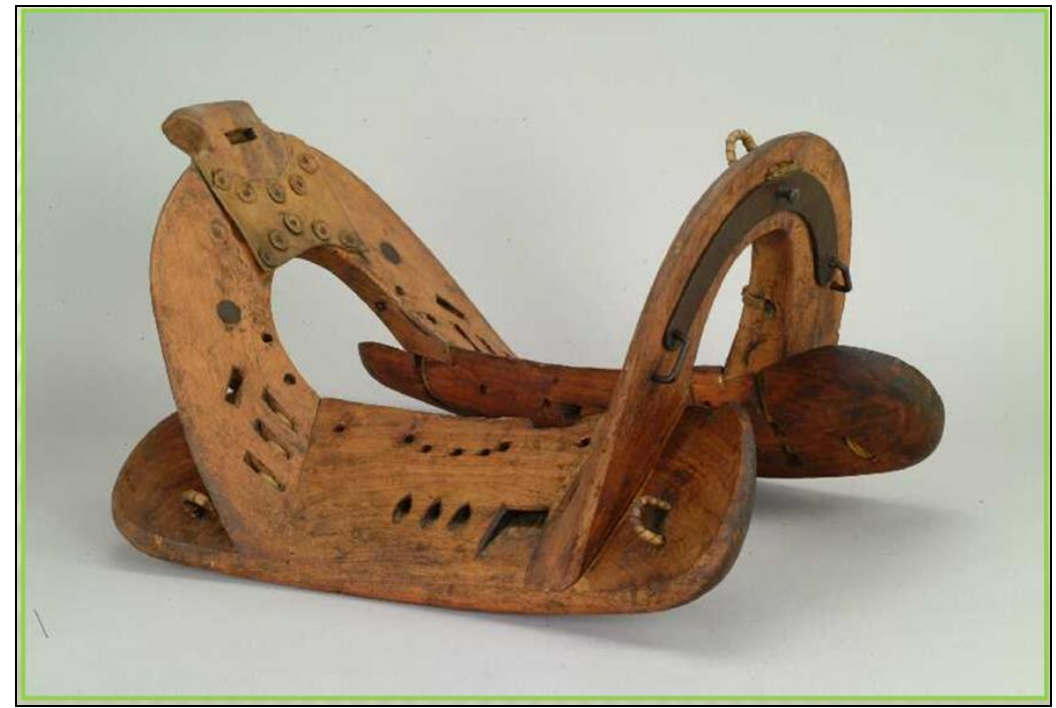

Bild. Nr. 14a: Einheitliches Kavallerie-Sattelgerüst mit Muster aus 1868. HM 94.115.1. 


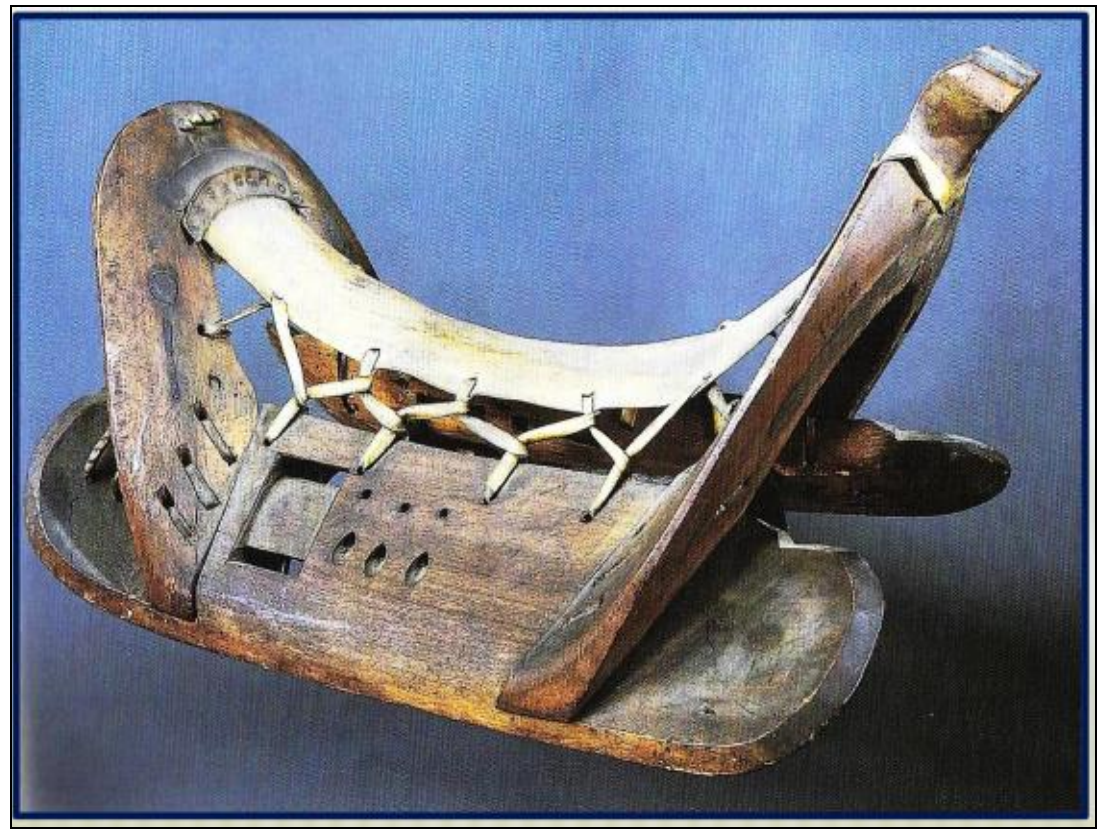

Bild. Nr. 14b: Militärsattel mit Lederbrücke, benutzt von Bawern. NM 60.108.2.

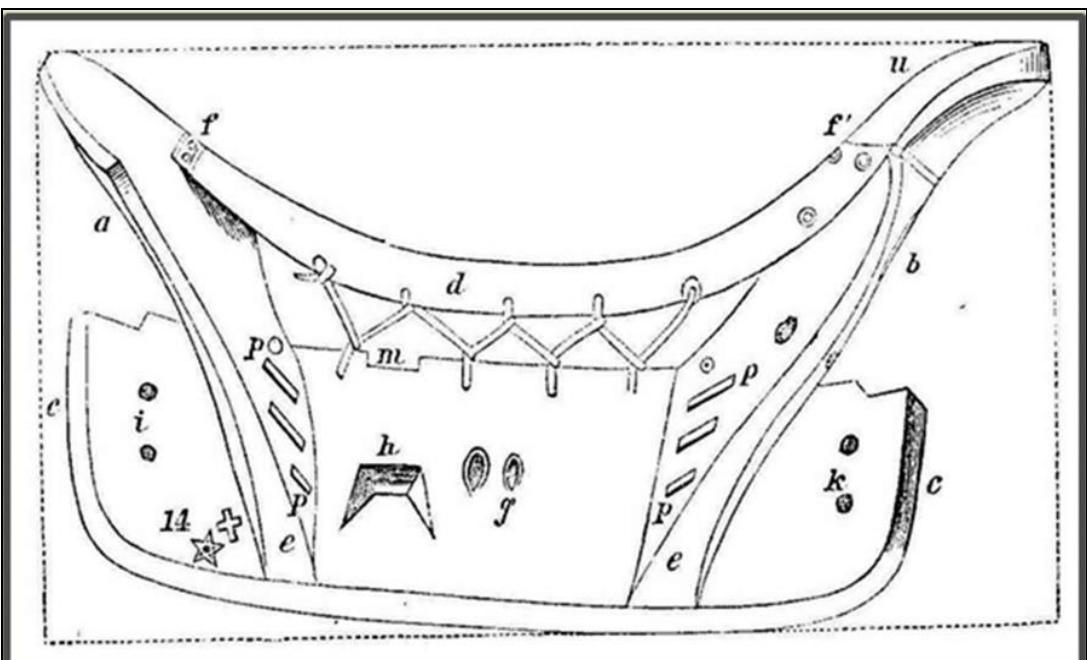

Bild. Nr. 15: Ungarischer Sattel: „Hungarian saddle“ (McClellan 1857). 


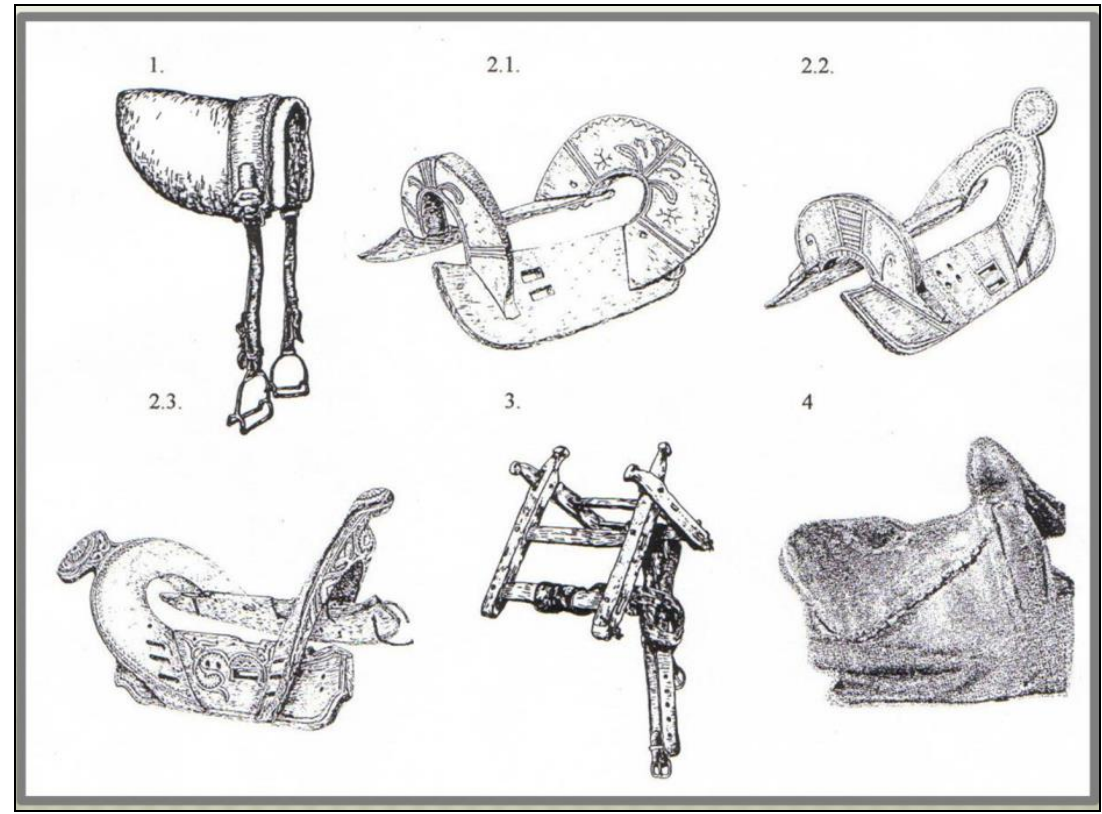

Bild. Nr. 16: Sattel-Grundtypen aus den Sammlungen des Ethnografischen Museums (Néprajzi Múzeum, Budapest).

\section{Die Sättelsammlung des Ethnografischen Museums (Néprajzi Múzeum, Budapest)}

Die größte Anzahl an Sätteln innerhalb der Bestände des Ethnografischen Museums (93 Stück) stammt aus der Sammlung für Verkehrswesen der Ungarischen Sektion. Aber auch die afrikanischen, asiatischen und europäischen Sammlungen der Internationalen Sektion enthalten nennenswerte Sattelbestände (35 Stück). Vereinzelt finden sich Sättel sowie Dokumentationen zu Sätteln auch in anderen Sammlungen, insofern bietet die gesamthafte Darstellung der einschlägigen Bestände gewisse Möglichkeiten für vergleichende Analysen. Die Ausstellung, die die Sammlung präsentierte, war wie folgt strukturiert: Sie wurde nach gesellschaftlichen Kategorien gegliedert, wie ländlichem Bauernstand, Bewohnern der Marktflecken, höheren Ständen, und vergleichsweise wurden die nicht-ungarischen Bestände anderer Völker einbezogen, insofern deren Reitkultur durch die Bestände des Museums dargestellt werden konnte. In dieser Hinsicht fiel die Sammlungspräsentation zwar bescheidener aus, aber mit Hilfe der zur Verfügung stehenden Gegen- 
Imre Gráfik

stände und der vergleichenden Fachliteratur wurde eine relativ umfassende Vorstellung der nicht-ungarischen Satteltypen ermöglicht.

Die ausgestellten Sättel aus den Sammlungen des Ethnografischen Museums gliederten sich aus technischer Perspektive in folgende Grundtypen:

1./ obne Sattelbaum, sog. Polstersattel

2./ Sattelgerippe aus Zwiesel, Sattelfuß

3./ gabelartige Seitenbrett-Gerippe

4./ sonstige individuelle Sattelgestelle

Geografisch betrachtet, waren nach Herkunfts-/Verwendungsort folgende Streuung vertreten:

- Große Tiefebene bzw. Tisza-Umland (mit Ortsbezeichnung): 37 Stück, davon: Hajdúböszörmény 8 Stück, Hajdúszoboszló 3 Stück, Botpalád 3 Stück, Túrkeve 3 Stück, Tis₹afüred 2 Stück, Tis₹abogdány 2 Stück, Komádi 2 Stück, Kecskemét-Bugac 2 Stück, Komitat Hajú 2 Stück, sonstige Siedlungen (je ein Exemplar) 10 Stück

- Einzugsbereich der Tiefebene (mit Ortsbezeichnung): 12 Stück, davon: Eger 6 Stück, sonstige Siedlungen (je ein Exemplar) 6 Stück.

- Übriges Ungarn (darunter mehrere, in der Hauptstadt erworbene Exemplare ohne Ortsbezeichnung): 23 Stück.

- Übriges Karpatenbecken (mit Ortsbezeichnung): 20 Stück.

Die Sättel der Ungarischen Sektion des Ethnografischen Museums sind hinsichtlich ihres Grundtyps überwiegend der 2. Kategorie (Zwiesel, Sattelfuß, Sattelgerippe) zuzuordnen. Aufgrund gewisser Merkmale können innerhalb der Grundarten weitere Untertypen bzw. viel eher Varianten unterschieden werden. Eine erzwungene Kategorisierung soll vermieden werden, insofern halten wir nur innerhalb der 2. Grundart eine weitere Typisierung für angezeigt, und zwar aufgrund der Unterschiede hinsichtlich der Ausformung der Zwiesel und deren Verbindungen zum Sattelfuß. In dieser Hinsicht gehören die Exemplare der Sammlungen der Ungarischen Sektion zu folgenden Grundarten und Untertypen:

Polstersattel: 5\%; 2.1. Ungarischer Sattel (Vorderer und hinterer Zwiesel enden im sog. Zwieselknopf, Verbindung aus Lederriemen und/oder verzapft, sog. Fahrledersitz): 10\%; 2.2. Ostungarischer/Siebenbürger Sattel (Hinterzwiesel ohne Kopf, sog. Rundausformung, verzapfte Verbindung): 11\%; 2.3. Tiszafüreder Sattel (Vorder- und Hinterzwiesel enden im charakteristischen sog. 
Zwiesellöffel, Verbindung aus Lederriemen, sog. Fahrledersitz): 55\%; 3. Lastensättel: 6\%; 4. Sonstige Sättel: 13\%.

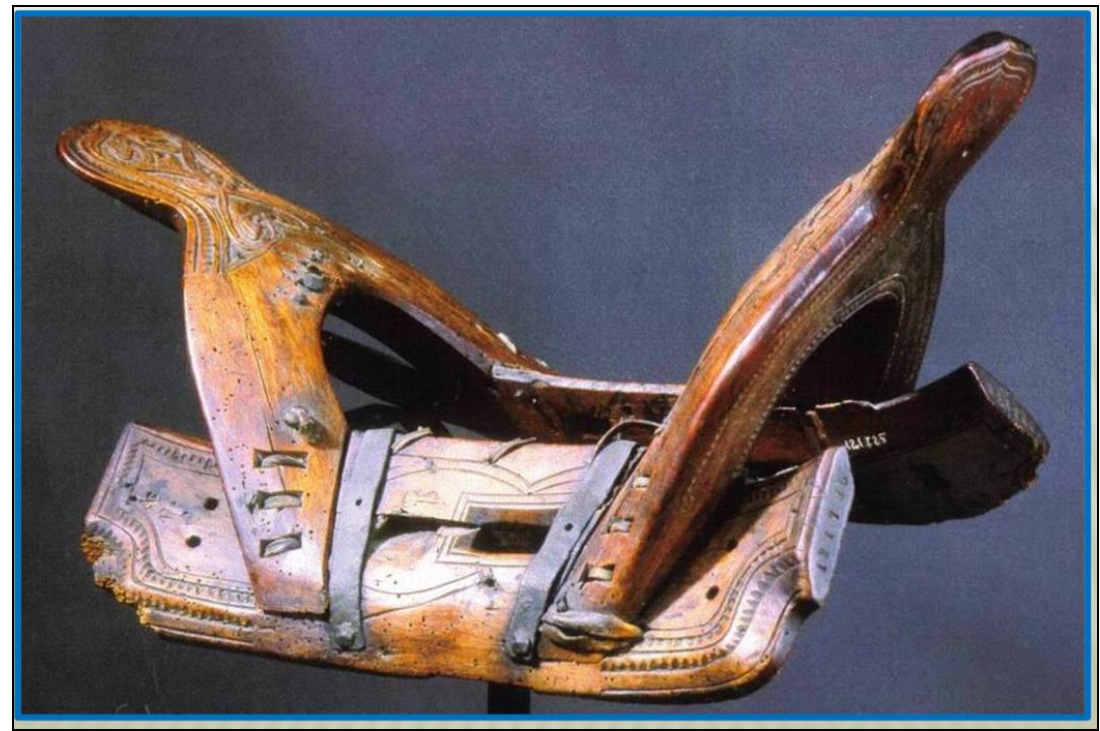

Bild. Nr. 17a: Sattel/Sattelgerüst. NM 121725.

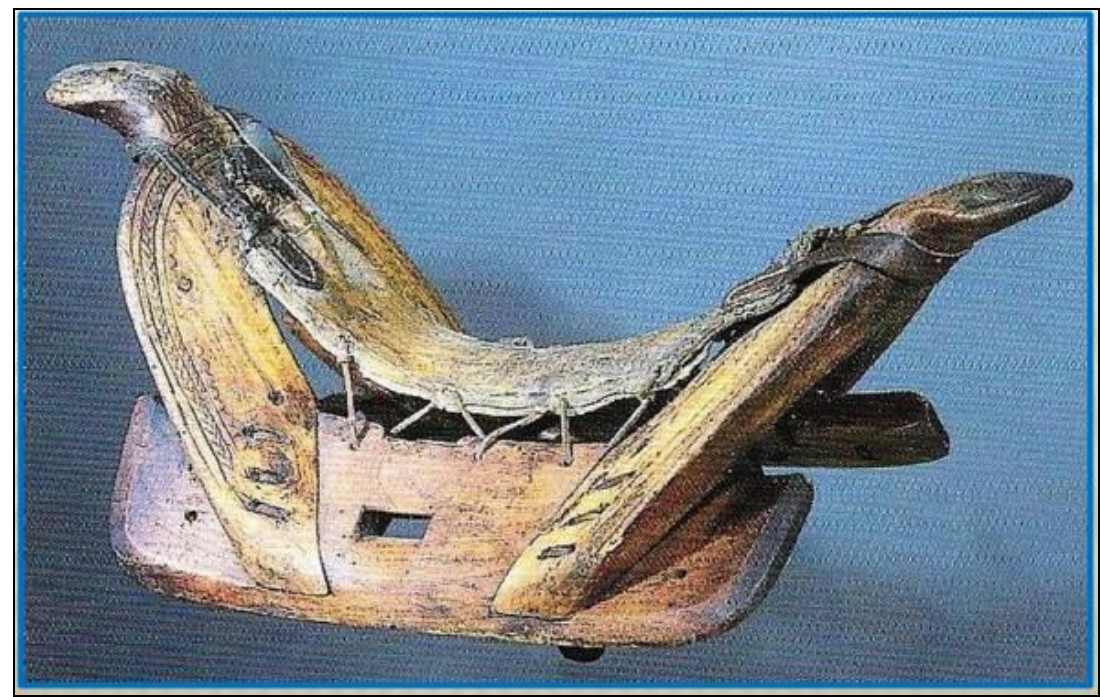

Bild. Nr. 17b: Sattelrahmen mit Lederbrücke. NM 69.106.3. 


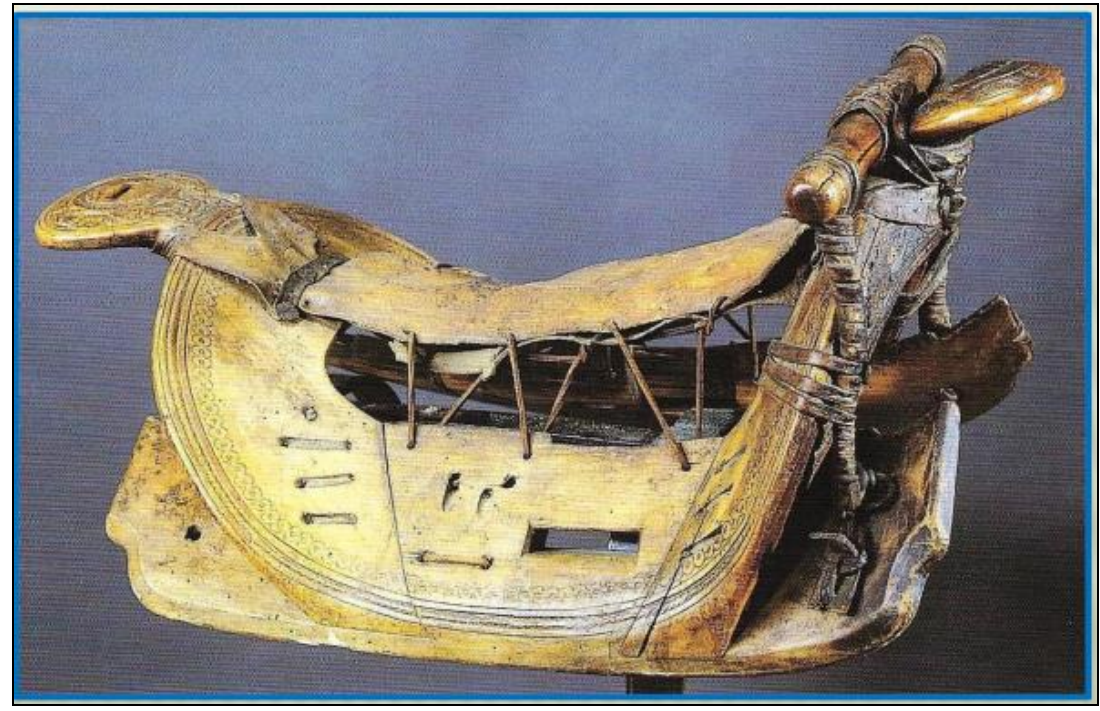

Bild. Nr. 17c: Sattelrahmen mit Kreuæstange. NM 78.63.4.

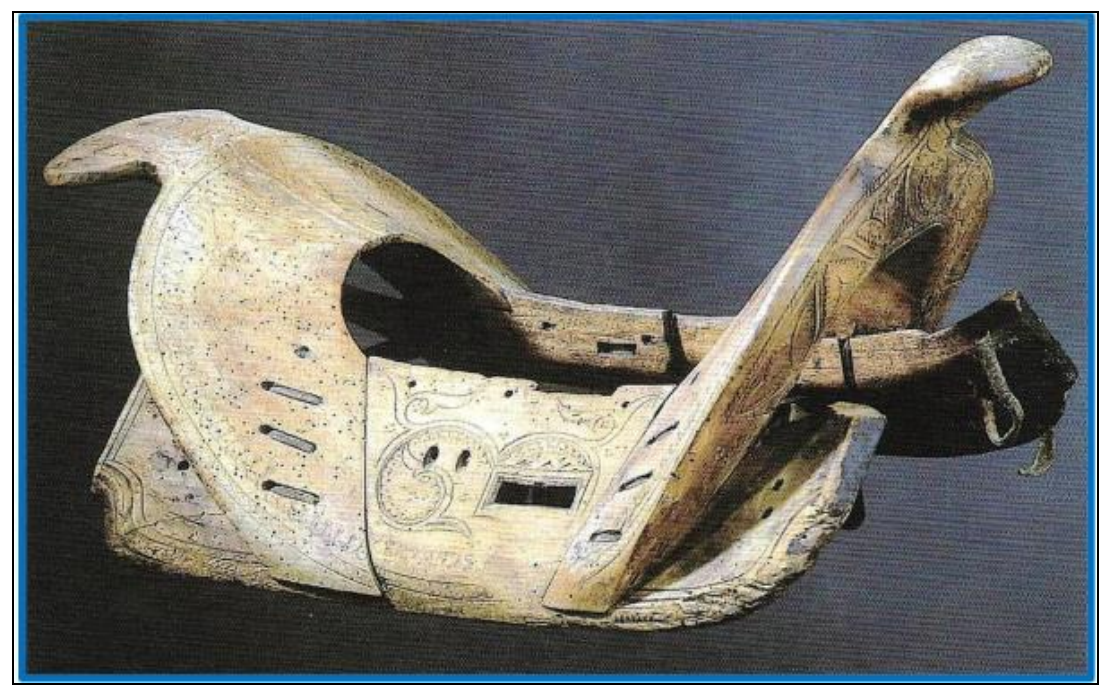

Bild. Nr. 17d: Sattel/Sattelgeriist. NM 56.32.157. 


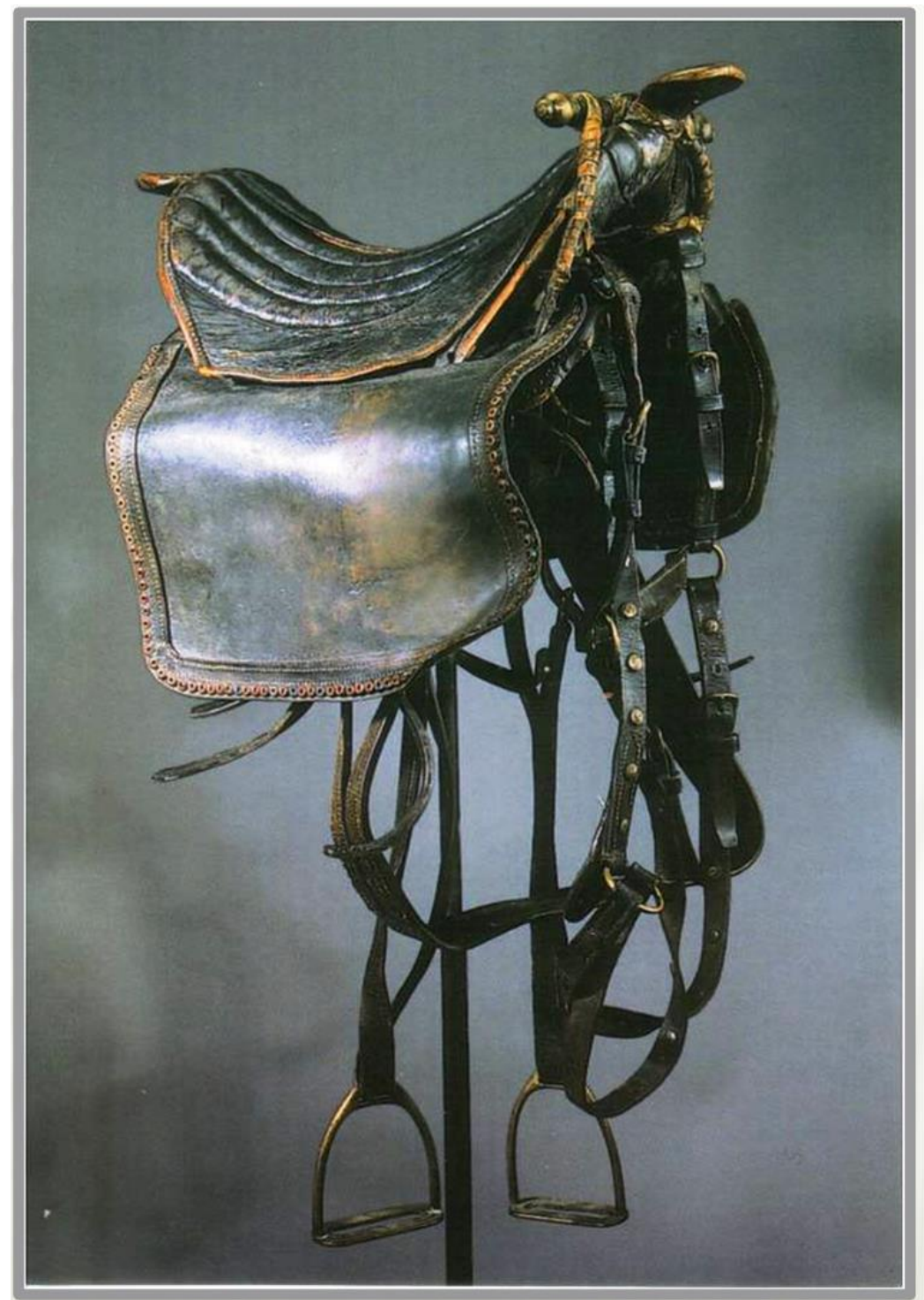

Bild. Nr. 18: Sattel mit voller Ausrüstung. NM 75.27.1.1-3.

In den Sammlungen der Internationalen Sektion des Ethnografischen Museums befinden sich Exemplare mit folgender Streuung: Afrika-Sammlung (insgesamt 5 Exemplare): Abessinien 1, Afrika 1, Alexandrien 1, Jemen 1, Marokko 1 Stück. Asien-Sammlung (insgesamt 26 Exemplare): Asien 6, Basch- 
kirien 1, Damaskus 1, Indien 1, Kaukasus 6, Kasachstan 1, China 2, Mongolei 1, Tibet 1, Turkestan 6 Stück. Europa-Sammlung (insgesamt 4 Exemplare): Finnland 4 Stück.

Die relativ kleine Sammlung ist in struktureller Hinsicht und im Hinblick auf die Ausstattung dezidiert vielseitig und reichhaltig. Typologisch fällt die Streuung folgendermaßen aus:

- Polstersattel: 6\%, 2. Zwiesel-Sattelfuß: 77\%, 3. Gabelartig-Seitenleiste/brett: $11 \%$, 4. Sonstige und Übergangsformen: $6 \%$.

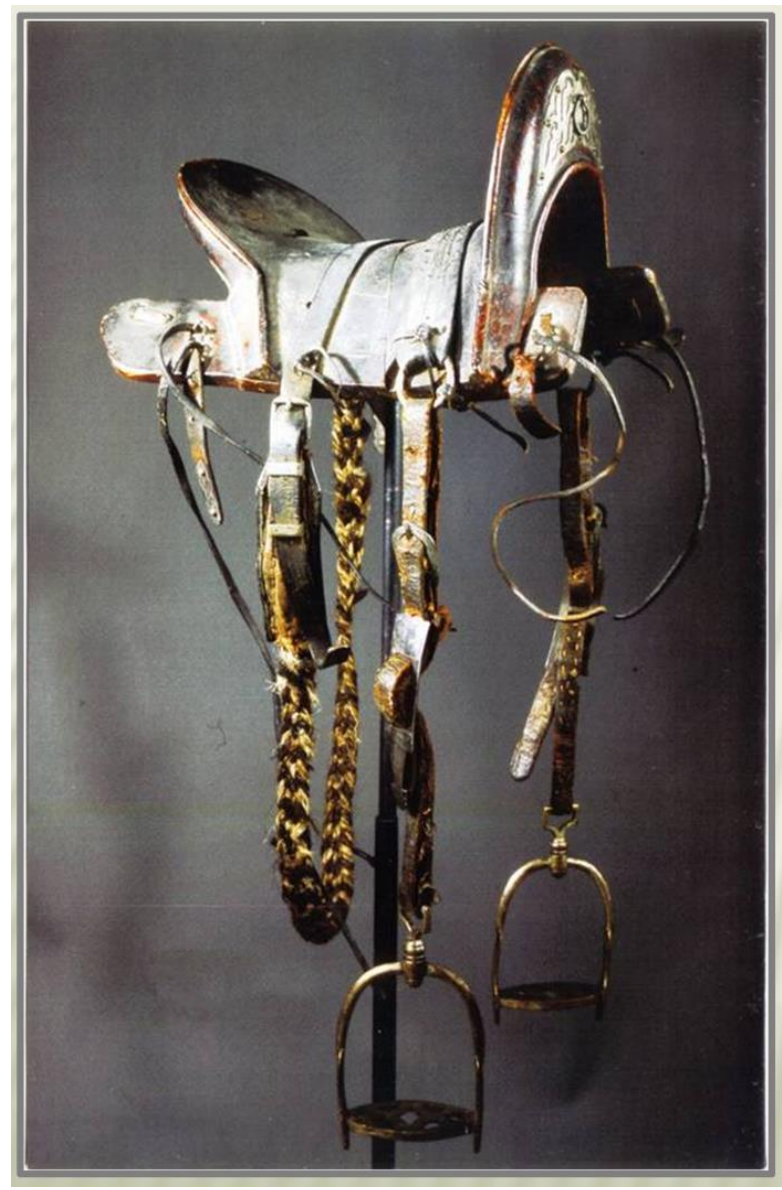

Bild. Nr. 19: Sattelausrüstung aus Bashkortostan. NM 79982. 


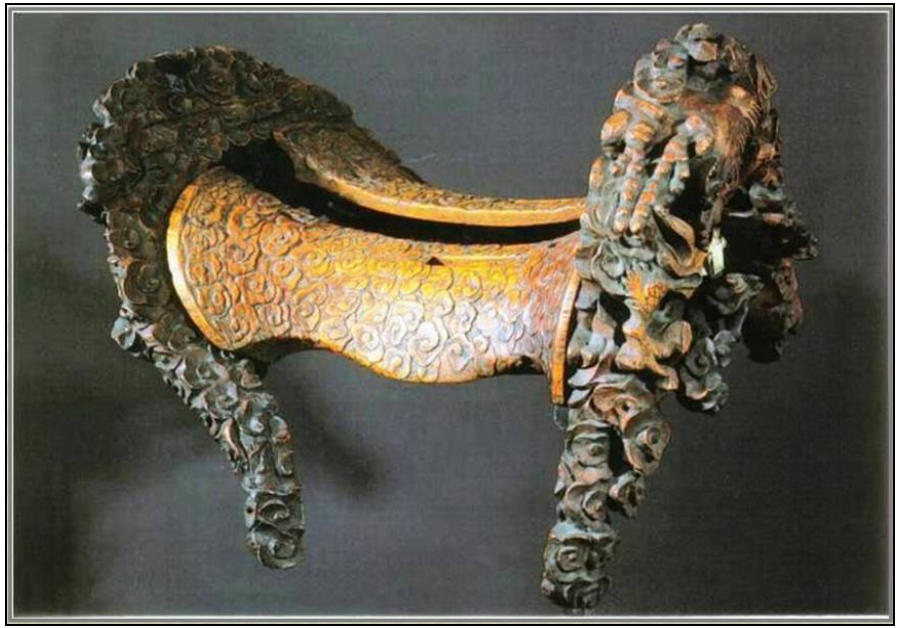

Bild. Nr. 20: Sattelrahmen/Sattelgerüst aus Japan. NM 75959.

\section{Die Sattelherstellung}

Hinsichtlich der Herstellung der ungarischen Sättel steht dem Ethnografischen Museum reichhaltiges, sich gegenseitig ergänzendes Quellenmaterial zur Verfügung. Das Wörterbuch von János Frecskay enthält eine allgemeine Einführung in die Arbeitsgänge und den Werkzeugbedarf der Sattelherstellung.

Die Handwerkliche Sammlung des Ethnografischen Museums gelangte in den Besitz mehrerer Werkzeuge aus der Werkstatt Mihály Kulis, des letzten der Tiszafüreder Meister. Die Sattlerei war überwiegend eine Familientradition, die über mehrere Generationen weitergegeben wurde. Gyula László hat aufgrund der Erinnerungen und der Berufserfahrung des Tiszafüreder Meisters eine akribisch ausführliche Beschreibung der Meistergriffe und der Arbeitsgänge für die Herstellung des Füreder Holzsattels veröffentlicht.

Wichtige Details zu den Prozessen der Sattelherstellung, den verwendeten Materialien und den verschiedenen technischen Kunstgriffen und Verfahren werden auch aus Analysen im Rahmen der Restaurierung einzelner Exemplare gewonnen.

Alles in allem erhalten wir ein klares Bild zu den Arbeitsgängen der Herstellung eines ungarischen (Tiszafüreder) Sattels. Die dargestellte Ausstellung verwertete dieses Wissen, indem sie das Innere einer Sattler- und Riemerwerkstatt als Rekonstruktion präsentierte. 


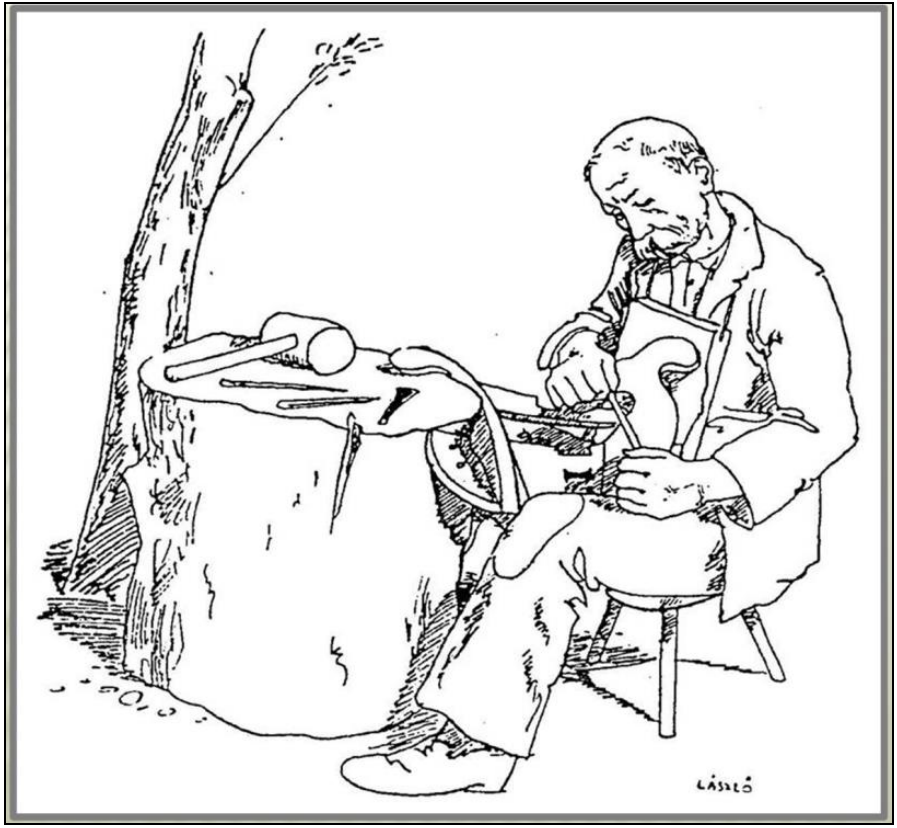

Bild. Nr. 21a: Sattelmeister während der Arbeit (László 1943).

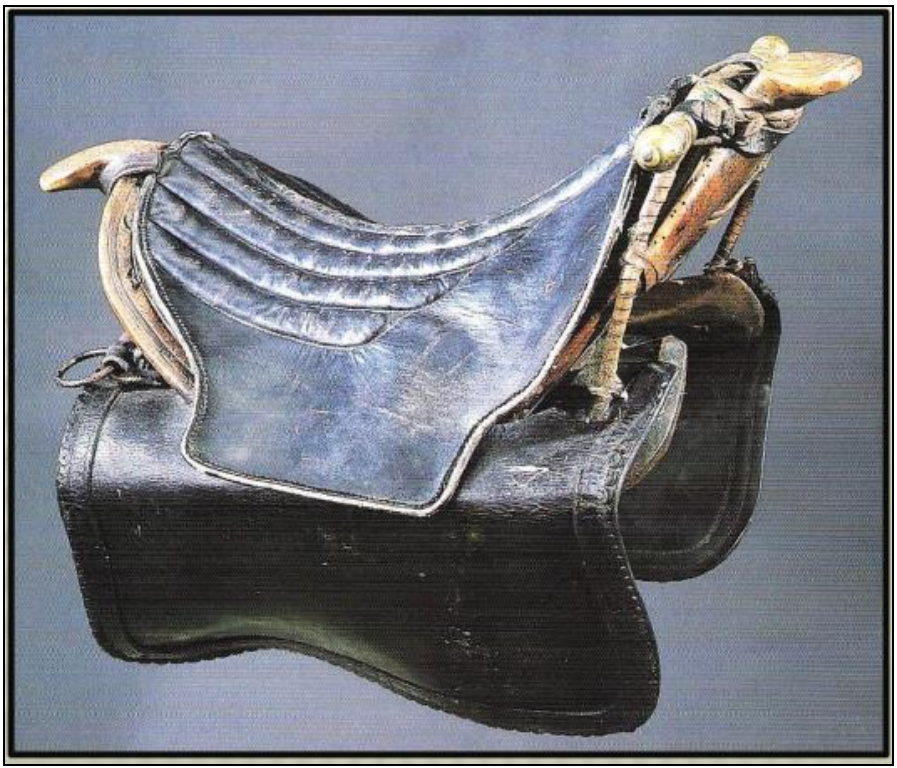

Bild. Nr. 21b: Sattel mit Lederkissen und Lederflügeln (Riemenhersteller). NM 67.153.1. 


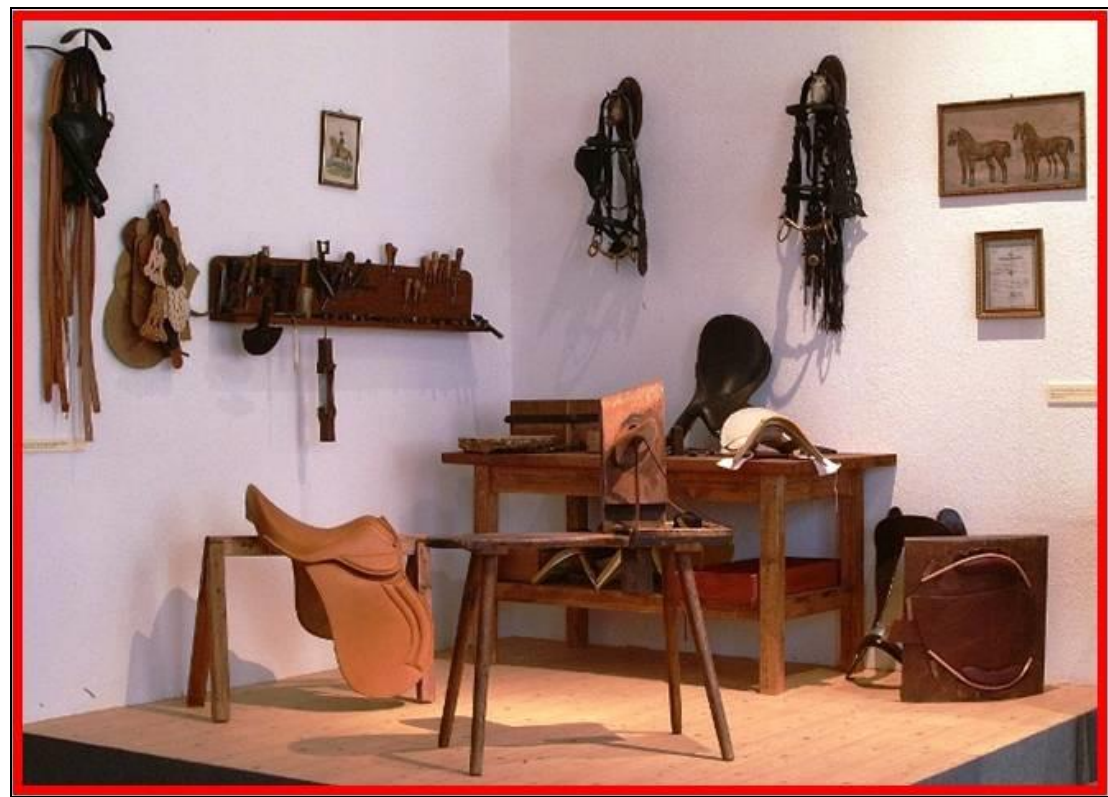

Bild. Nr. 22: Rekonstruierte Sattler-und Riemerwerkstatt in der Ausstellung (Familie Pánczél).

\section{Die Verzierung der Sättel}

Die Sättel wurden vor dem Aneinanderfügen des Sattelfußes und des Zwiesels verziert. Holzsättel wurden mit Schnitzwerk versehen und mit Punkt-Strich-Motiven, Blumen und sonstigen folkloristischen Motiven bemalt. Selbstverständlich wurden auch schmucklose Gebrauchssattel hergestellt.

Die wichtigsten Werkzeuge zur Verzierung waren das Zackeneisen, das Schnitzmesser, der kleine Stechbeitel und der Holzhammer. Mit dem Zackeneisen wurden Kreise, Halbkreise und Keilformen verschiedener Größe ins Holz getrieben. Mit Hilfe des Schnitzmessers wurden die Kunstschnitzereien hergestellt. Mit dem kleinen Stechbeitel wurden verschiedene Muster in die Holzoberfläche geschlagen.

Die am meisten verzierten bzw. betonten Teile des Sattels waren die Zwiesel und die Seiten der Sattelköpfe. Oft wurde nur die Außenseite verziert, aber es gibt mehrere Beispiele dafür, dass auch die Innenseite reich und anspruchsvoll verziert wurde - mitunter reichhaltiger und arbeitsintensiver als die Außenseite. 
Die neuesten ethnografischen Forschungen haben neue Details zur Erstellung der Verzierungen der Tiszafüreder Holzsättel an den Tag gebracht und haben unser Wissen um weitere Zierelemente, Formen und Motive erweitert.

Hinsichtlich der Verzierung verdienen die sogenannten Knochensättel des Ethnografischen Museums eine gesonderte Erwähnung. Typologisch gesehen sind diese Exemplare den ungarischen Sätteln zuzuordnen, in ihren strukturellen Eigenschaften und ihrer Form kommen sie im Wesentlichen dem Tiszafüreder Typ nahe, doch stellen sie eine besondere, hochstehende Variante des Sattler-Kunsthandwerks dar.

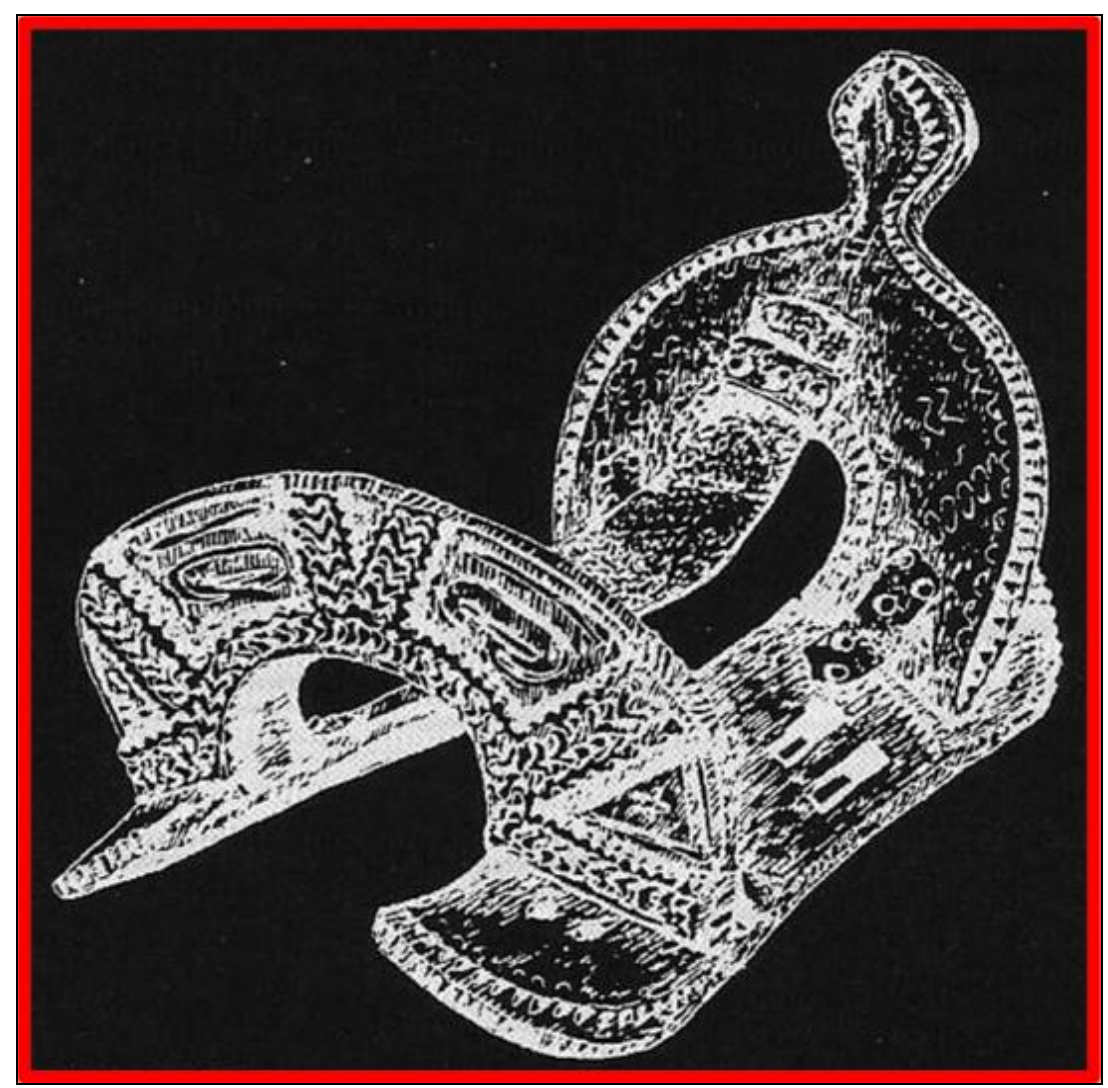

Bild. Nr. 23a: Sattelrahmen mit versenkter Schnitzerei. NM 38945. 


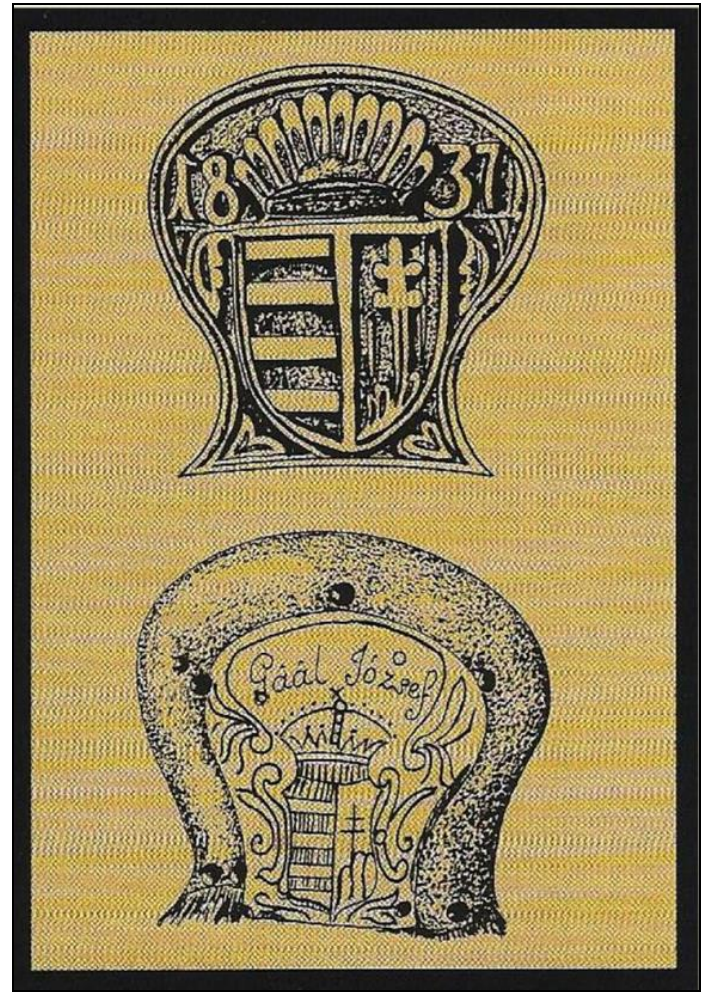

Bild. Nr. 23b: Wappenschnitzereien auf Sättelköpfen.

\section{Gebrauch der Sättel}

Die Erforschung der Urgeschichte des Ungarntums zeigt, dass die Reitkunst bereits fester Bestandteil des finno-ugrischen Kulturkreises war. Die zahlreichen Funde von Zaumzeug in den Ausgrabungen der Ananyinoer Kultur zeugen weniger von Bejochung als vielmehr von der Nutzung des Pferdes als Reittier.

Zusammenfassend kann festgestellt werden, dass je einfacher das Sattelgerippe und die Ausstattung gehalten war, desto eindeutiger war der Sattel für einen alltäglichen Gebrauch bestimmt, gegebenenfalls speziell für eine bestimmte Tätigkeit, einen bestimmten Zweck. Je anspruchsvoller und reicher ein Sattel verziert und je umfangreicher die Ausstattung war, desto wahrscheinlicher diente er repräsentativen und protokollarischen Zwecken bzw. wurde er zu Festzeiten verwendet. Wir haben ein Experiment auf der Ausstellung gemachtund durch Darstellungen, Fotos sowie Film- und Videoclips 
vom verschiedenartigen Gebrauch des Sattels bis hin zum Sportreiten, zum therapeutischen Reiten (sog. Hippotherapie) und zum Reittourismus ein lebendiges Bild vermittelt. Ein Sonderraum ist dem Andenken an die Glanzleistungen des ungarischen Pferdesports gewidmet (Kincsem, Imperial). Eine weitere Einheit ist den heutigen Bemühungen vorbehalten, die Traditionen der Reitkultur einschließlich des Tourismus am Leben zu erhalten.

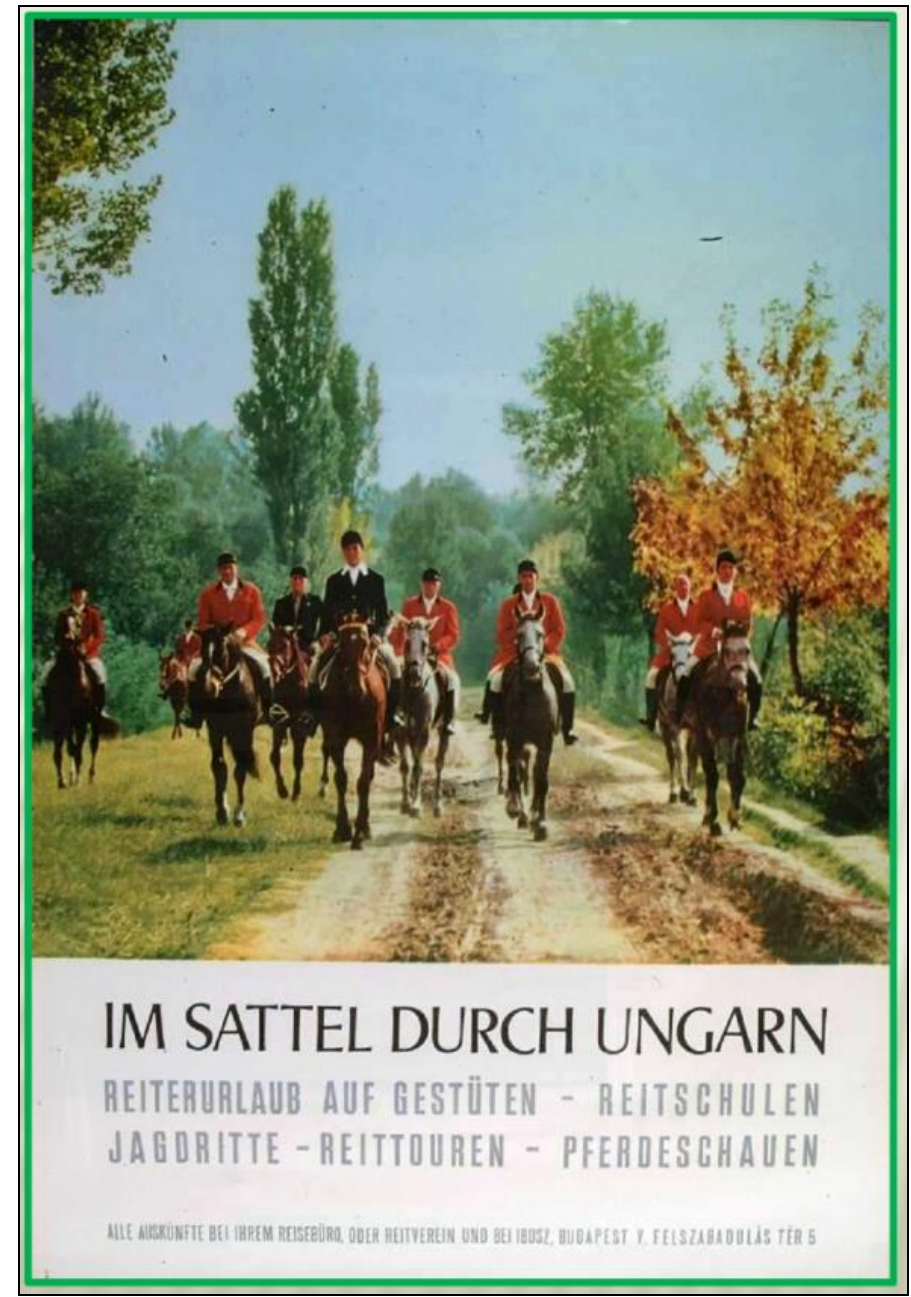

Bild. Nr. 24a: Fremdenverkehrsplakat 1960 (Privatsammlung). 


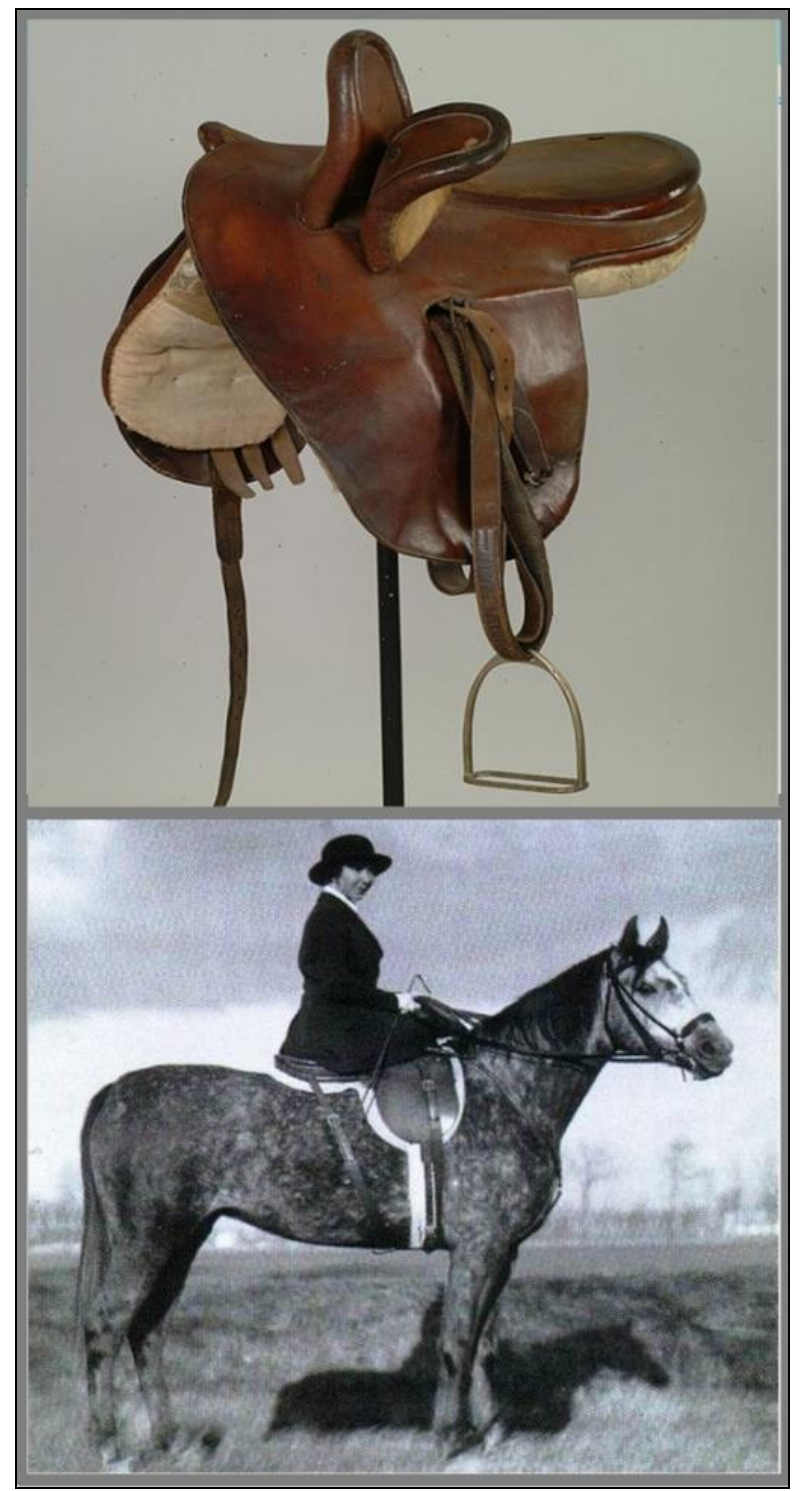

Bild. Nr. 24b: Damensattel (MMM 56.82.1)

und reitende Dame (MMM WB 2077). 


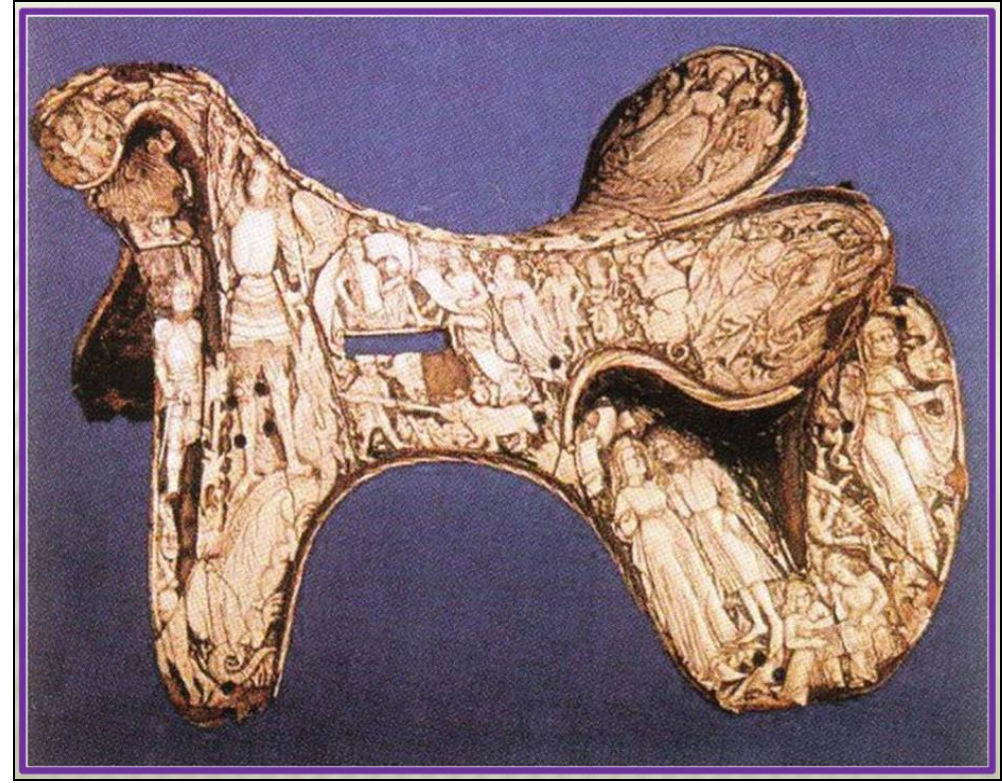

Bild. Nr. 25: Knochensattel, 15. Jabrbundert, aus der Sammlung von Kázmér Batthyány. MNM 55.3117 (Temesváry 1995)

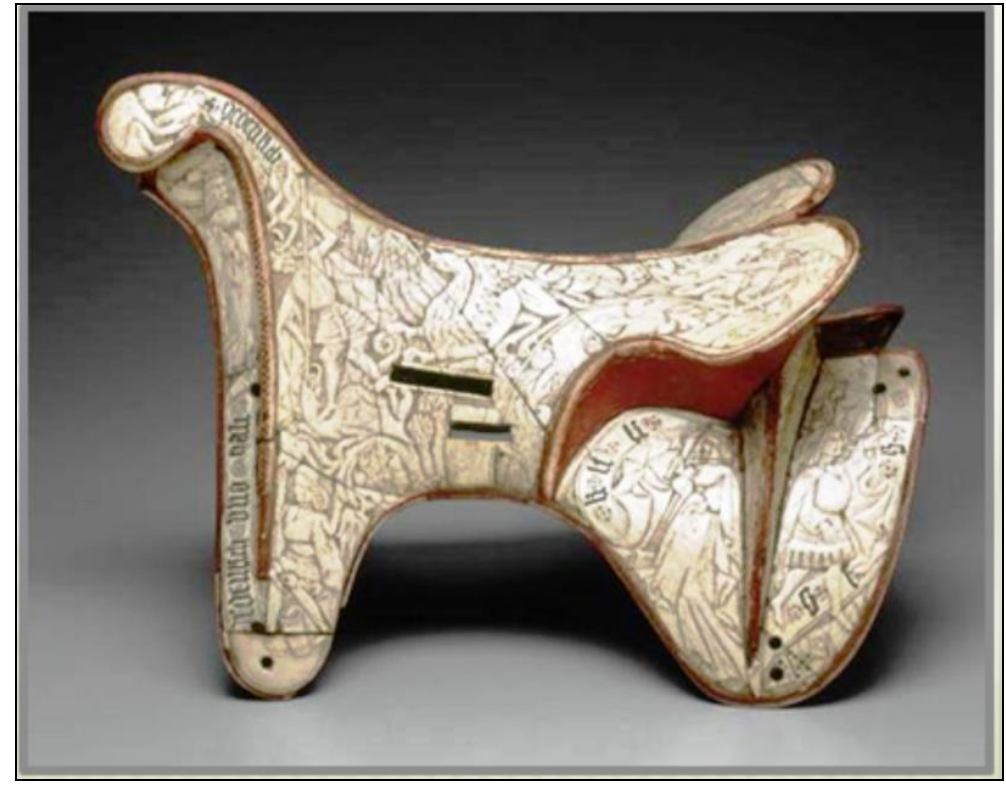

Bild. Nr. 26: Knochensattel, bekannt auch als „Körmend Sattel“ oder „BatthyanyStrattman Sattel", 15. Jahrhundert. Boston, Museum of Fine Arts 69.944. 


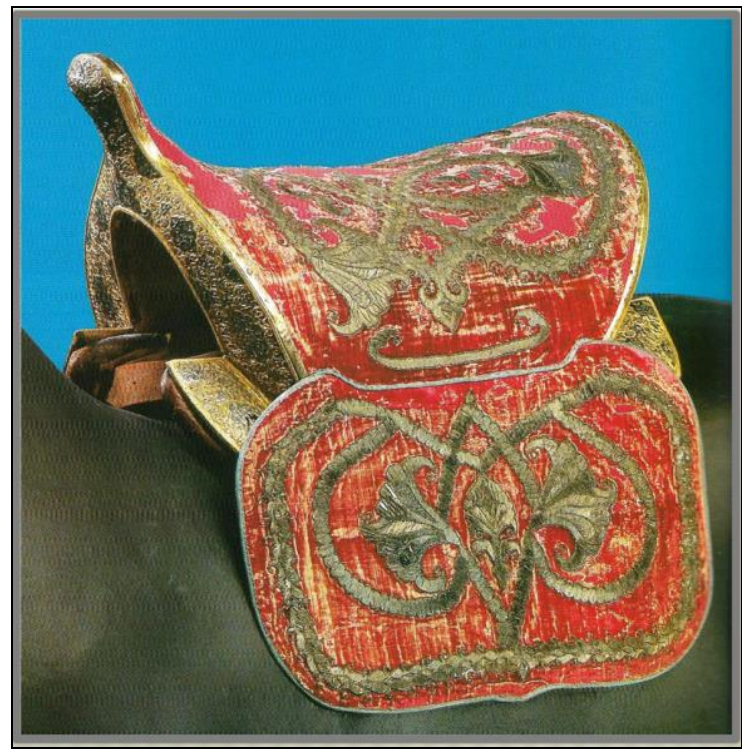

Bild. Nr. 27: Türkischer Sattel von Sámuel Teleki mit Silber verziert, 17. Jahrhundert. MMM 55.3561. (Temesváry 1995)

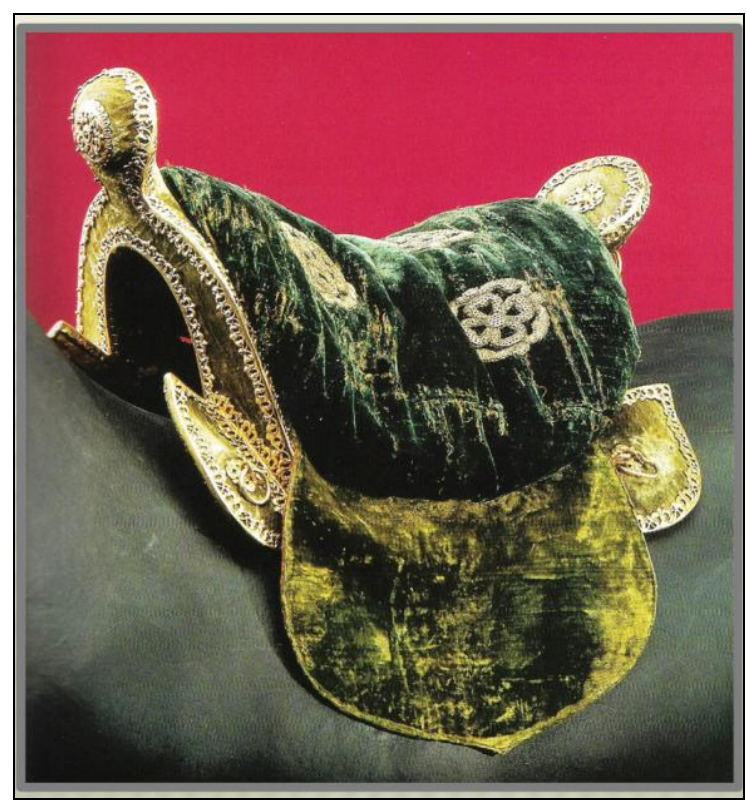

Bild. Nr. 28: Ungarischer Sattel (Füreder Typ),

18. Jahrhundert. MNM 57.6706. (Temesváry 1995) 
Heutzutage kann beobachtet werden, dass das Interesse an der Geschichte und den Traditionen der Reitkultur wieder im Steigen begriffen ist. Das neue Interesse mag zwar dazu verleiten, zu idealisieren, trotzdem ist zu begrüßen, dass der gute alte ungarische Holzsattel wieder dem Dunkel der Vergangenheit entrissen wird, hat sich dieser doch über Jahrhunderte hinweg bewährt. Wir sind praktisch Zeugen einer Wiederbelebung von für vergangen gehaltener Traditionen: Sattler studieren die alten Exemplare und erstellen Rekonstruktionen, und es wird sogar an einer Weiterentwicklung des bewährten Holzsattels vom Tiszafüreder Typ gearbeitet, der heutigen Anforderungen entsprechen soll. Die obengenannte Ausstellung präsentierte auch die Versuche gewisser Handwerker und Firmen, das historische Erbe weiterzuvermitteln.

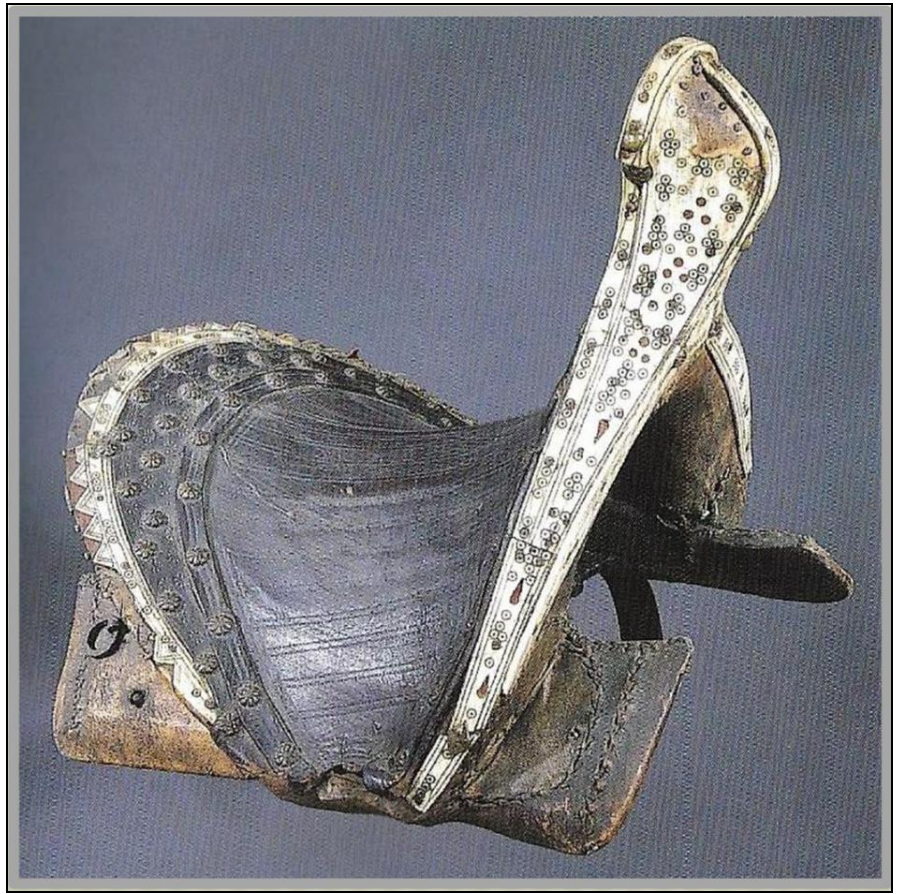

Bild. Nr. 29: Knochensattel, sogenannter Bocksattel, 17. Jahrhundert. NM 134692.

Bis zu seiner Verdrängung als Gebrauchsgegenstand war der ungarische Sattel im Leben der ländlichen Bevölkerung ein allseits geschätzter Bestandteil des Alltags und auch ein Zeichen der Repräsentation und der 
Festfreude. Die Ziersättel avancierten im Kreise der Adelsfamilien mitunter zu wahrhaftigen Familienikonen.

Die Schlussfolgerungen und Feststellungen aus dem reichhaltigen, aber hinsichtlich Zeit und Raum, Menge und Qualität doch gewissen Beschränkungen unterliegenden Bestand sind erzwungenermaßen von beschränkter Gültigkeit. Die Entwicklungsgeschichte der verschiedenen Sattelvarianten kann in groben Zügen als bekannt vorausgesetzt werden, doch sehen wir uns in vielen Details noch unbeantworteten Fragen gegenüber. Wir hoffen, dass auch diese Studie Anhaltspunkte für die weitere Erforschung der noch unklaren Bereiche bietet. Durch das Aufwerfen der bislang unbeantworteten Fragen beabsichtigen wir, zu deren fachlicher und wissenschaftlicher Klärung anzuspornen.

Zum Schluss erinnern wir uns an die Besonderheit des östlichen Satteltypus', der Ausdruck einer intimen Beziehung und gegenseitigen Wertschätzung zwischen Mensch und Pferd ist und ein selbstredendes Zeugnis der Bestrebung darstellt, die Harmonie zwischen dem Tier und seinem Halter aufrechtzuerhalten. Sowohl die Baschkiren als auch die Kirgisen waren sehr bestrebt, jedem Aufreiben des Pferderückens zuvorzukommen. Ein kirgisischer Spruch besagt: Attin arkaszin bosquan ijerni, altin hoszti bolszada otka zsak - einen Sattel, der den Rücken deines Pferdes aufreibt, sollst du selbst dann verbrennen, wenn sein Kopf aus Gold wäre.

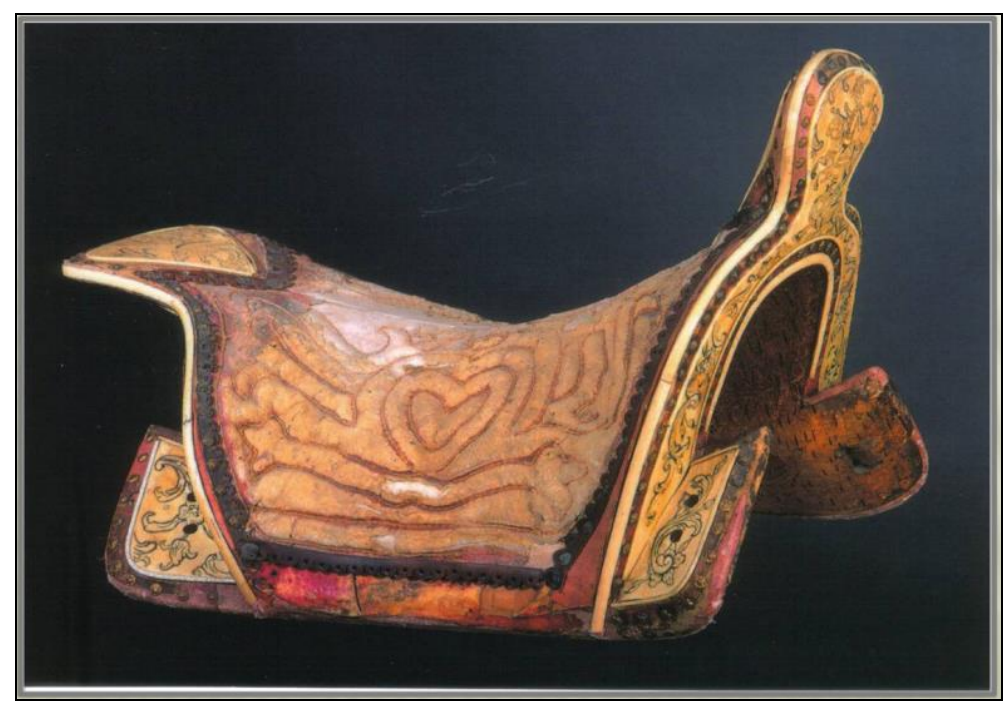

Bild. Nr. 30: Knochensattel, 17.-18. Jahrhundert. NM 60.108.20. (Torma 1979) 


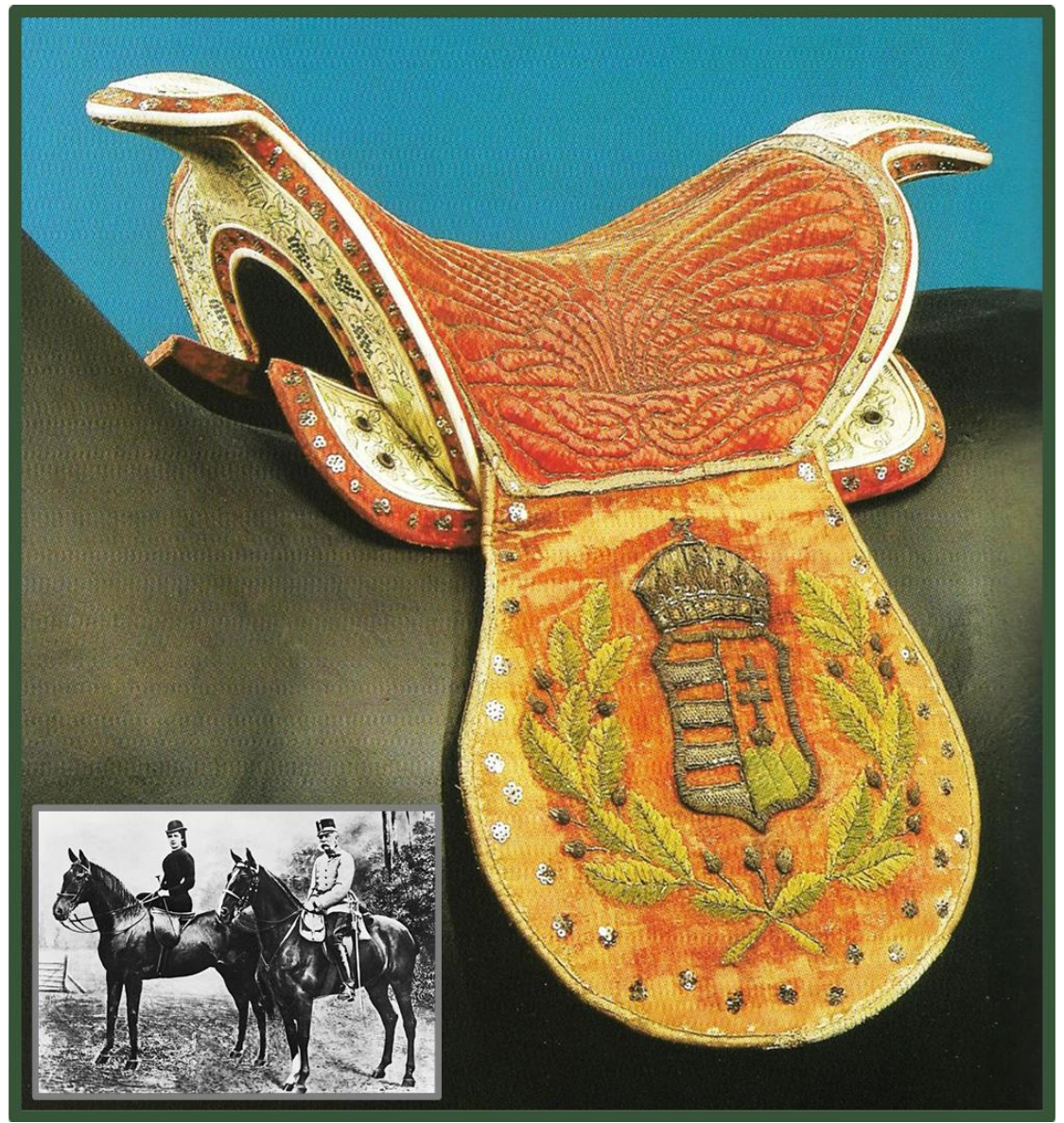

Bild. Nr. 31: Kaiser Franz Josephs Sattel. (Hergestellt von József Majomy im Jahre 1857 Rimaszombat.) MMM 57.6702 (Temesváry 1995) -

Bild im Bild: Sissi, dh. Königin Elisabeth von Ungarn und Kaiser Fran₹ Joseph von Österreich und König von Ungarn. Quelle: Kovács 2019. 


\section{Literatur}

BEATIE, Russel H.

1981 Saddles. Norman: University of Oklahoma Press

FRECSKAY, János

1912 Mesterségek sqótára. Budapest: Hornyánszky Viktor Császári és Királyi Udvari Könyvnyomdája

FÜVESSY, Anikó

2007 A tiszafüredi fanyergek korai díszítőstílusa. Faragótechnika, motívumok és kompozíció elrendezés szerepe a kormeghatározásban. Ethnographia. 118. 1. 181-202.

GARAY, Ákos

1936 Magyar nyergelés. Néprajzi Értesitő. 28. 110-113.

GIRODET, Jérôme

2017 L’histoire des Hussards. Tarbes: Musée Massey

GRÁFIK, Imre

2001a Magyar nyereg - huszár nyereg - tiszafüredi nyereg - keleti kulturális örökség. Ethnographia. 62. 1-2. 81-124.

2001b Ungarischer Sattel - „Der Tiszafüreder Holzsattel” - kulturelle Erbe vom Osten. In Seilethal, Tönu (Hg.): FU 9 Pars VII. Dissertationes sectionum: Folkloristica \& Ethnologia. 339-345. Tartu: Congressus

2002a A nyereg. A Néprajzi Múzeum tárgykatalógusai - Catalogi Musei Ethnografhiae. 6. Budapest: Néprajzi Múzeum

2002b Nyeregbe! In the Saddle! Fest im Sattel! 22 März 2002. - 10 September 2002. Budapest: Néprajzi Múzeum

2002c The Hungarian Saddle. Exibition at the Museum of Ethnography between March 21 to 10 September 2002. Hungarian Heritage 3. 1-2. 96-106.

2002d Jeles nyergek. In Csonka-Takács Eszter - Czövek Judit - Takács, András (Hrsg.): Mir-susne-xum I. Tanulmánykötet Hoppál Mibály tiszuteletére. 333-350. Budapest: Akadémiai Kiadó

2003a A magyar nyereg és használata. In Frisnyák Zsuzsa (Hg.): Közlekedés a Kárpát-medencében. Újabb kutatási eredmények. 69-90. Budapest: Közlekedési Múzeum.

2003b Lovas turizmus - lovashagyomány. (Gondolatok egy kiállítás kapcsán) In Fejős Zoltán - Szijártó Zsolt (Hrsg.): Helye(in)k, tárgya(in)k, képe(in)k. 209-227. Budapest: Néprajzi Múzeum

2004a Marked object: Signs on the saddles. Semiotica. 150. 1. 537-577.

2004b A lovaglás és a nyereghasználat emlékei Nyugat-Dunántúlon (Vas megyében). Vasi Szemle. 58. 4. 395-426.

2004c A huszár alakja a magyar népmüvészetben. In Zachar József (Hg.): A magyar huszárság története - A lovasműveltség sajátosságai. 88-102. 
Budapest - Zürich: Zürichi Magyar Történelmi Egyesület és Heraldika Kiadó

2004d Nyeregbe Európa!/V sedlo, Evropa!/In the saddle, Europe! In Zdravic Polic, Nina (Urednica kataloga/Hg.): Evropski etnografski muzej v SEM - European Ethnographic Museums in SEM 2. December 2004 - December 2005. 38-39. Ljubljana: Slovenski etnografski muzej

2004e Megjelölt tárgyak - jelek nyergeken. Néprajzi tárgyak vizuális/szemiotikai értelmezése. Néprajzi Értesitó. 86. 25-48.

2005a Hungarian saddle - Tiszafüred saddle - Eastern cultural heritage. Acta Ethnographica Hungarica. 50. 1-3.1-37.

2005c Újabb adatok Nyugat- és Közép-Dunántúl nyereghasználatához. Vasi Szemle. 59. 3. 313-321.

2006 Keleti kulturális örökségünk: a nyereg. Néprajæi Értesitó. 87. 9-39.

2014 A nyereg, mint hungaricum, és lovas kultúránk lehetőségei. In Báti Anikó - Csoma Zsigmond (Hrsg.): Középkoori elemek a mai magyar anyagi kultúrában. Életképek a Kárpát-medence anyagi kultuirája köréböl I. 6-87. Budapest: Agroinform Kiadó és Nyomda Kft.

H. TÓTH, Elvira

1976 The Equesterian Grave of Izsák-Balázspuszta from the Period of the magyar Conquest. Cumania. 4. 141-184.

KOVÁCS Noémi

2019 A szemünk előtt robbant fel a Lánchíd. https://www.origo.hu/tudomany/20190810-vegigjartunk-budaviharos-tortenelmenek-fontosabb-allomasait.html - 05.05.2021.

LAKING, Sir Guy Francis

1920 A record of European Armour and Arms through seven centuries III. London: G. Bell and Sons

LÁSZLÓ, Gyula

1943 A koroncói lelet és a honfoglaló magyarok nyerge - Der Grabfund von Koroncó und der altungarische Sattel. Archaeologia Hungarica. 27. Budapest: Országos Magyar Történeti Múzeum

1974 A népvándorláskor müvészete Magyarországon. Budapest: Corvina

MCCLELLAN, George B.

1857 Report of the Secretary of war: communicating the report of Captain George B. McClellan ... one of the officers sent to the seat of war in Europe, in 1855 and 1856. Washington: A.O.P. Nicholson

TEMESVÁRY, Ferenc

TORMA, László

1995 Diszes nyergek, lószerszámok. Budapest: Dunakönyv Kiadó

1979 Magyar csontos nyereg XVIII. századból. In Párdányi Miklósné (Hg.): Múzeumi mútárgyvédelem. 6. 171-189. Budapest: Múzeumi Restaurátorés Módszertani Központ 
U. KÖHALMI, Katalin

1968 Two Saddle Finds from Western Mongolia. Acta Archaeologica Hungarica. 20. 347-358.

1972 A sqtyeppék nomádja lóháton, fegyverben. Budapest: Akadémiai Kiadó ZACHAR, József (Hg.)

2000 The Hungarian hussar. An illustrated history. Budapest: Corvina Kiadó SOMOGYVÁRI, Virág

2018 "Laugh, My Love, Laugh:” Mottos, Proverbs and Love Inscriptionson Late Medieval Bone Saddles. In Jaritz, Gerhard - Lyublyanovics, Kyra - Drosztmér Ágnes (Hrsg.): Annual of Medieval Studies at CEU. 24. 113128. Budapest: Central European University Budapest Department of Medieval Studies Central European University

\section{Abkürzungsverzeichnis}

HM - Hadtörténeti Múzeum (Militärhistorisches Museum), Budapest

MMM - Magyar Mezőgazdasági Múzeum (Ungarisches Landwirtschaftsmuseum), Budapest

MNM - Magyar Nemzeti Múzeum (Ungarisches Nationalmuseum), Budapest

NM - Néprajzi Múzeum (Ethnographisches Museum), Budapest

Korrektorleser: Hans-Werner Retterath 